\title{
Hazard communication by volcanologists: part 2 - quality standards for volcanic hazard assessments
}

\author{
Richard J. Bretton ${ }^{1 *}$ D, Joachim Gottsmann ${ }^{1}$ and Ryerson Christie $^{2}$
}

\begin{abstract}
Contextualisation is the critical process of interactions between volcanologists and risk governance decision-makers and specifically the tailoring of hazard assessments to ensure they are driven by the needs of decision-makers. Quality assurance standards for the contextualisation of the analysis and communication of volcanic hazards do not formally exist. For volcanologists this governance lacuna creates a foreseeable and avoidable managerial hazard. This is the second of two papers that together investigate the interface between the scientific treatment of volcanic hazards and the governance of volcanic risks. Both papers are principally concerned with issues of risk governance and their focus is hazard communication by volcanologists at this hazard-risk interface (the interface) during periods of volcanic unrest. In our first paper "Hazard communication by volcanologists: Part 1 - Framing the case for contextualisation and related quality standards in volcanic hazard assessments", (Bretton et al, J Appl. Volcanol. DOI 10.1186/ s13617-018-0077-x, 2018) we investigated the perceived qualities of more 'socially robust' hazard assessments and argued that the working practices of contextualisation must be more methodical.

In this paper, we focus on the actual process of contextualisation and argue that quality assurance standards need to be devised and adopted by volcanologists undertaking hazard assessments that are robust enough to bear legal scrutiny. Such standards are necessary: (1) to facilitate a more structured approach to contextualisation; (2) to preserve the core values of traditional scientific methodologies; (3) to address a working assumption that, in the absence of effective regulation, the 'equilibrium of contextualisation' may be unduly influenced by the demands of decisionmakers; and (4) to mitigate the managerial risks related to volcanologists assuming responsibility for contextualisation. Our initial literature review reveals the realities of contextualisation in the absence of effective regulation and identifies many of the foreseeable practical challenges historically faced by volcanic hazard assessors. We investigate and characterise these challenges in order to develop quality standards tailored for practical use. In addition, we present new empirical data acquired from a survey of 33 experienced volcanologists, 18 of whom were selected for one-to-one semi-structured interviews. The survey captures a snapshot of working practices and related sentiments that might indicate whether a more structured approach to contextualisation would find favour amongst volcanologists and, if so, what principles of contextualisation would be most acceptable. This evaluation of published evidence and new data permits us to identify seven aspects of volcanic hazard assessments relevant to quality assurance - the methods and status of hazard analyses, and the delivery, content, status, perception and advice content of hazard communications. Our proposed quality standards and related proto-type code of practice together address issues of materiality, comprehensibility, proximity and integrity. They offer the possibility of hazard assessments having greater validity and utility in that they will be framed by reference to the sentiments and actions of their users.
\end{abstract}

Keywords: Hazard, Risk, Risk governance, Communication, Contextualisation, Deliberation

\footnotetext{
* Correspondence: richard.bretton@bristol.ac.uk

${ }^{1}$ School of Earth Sciences, University of Bristol, Wills Memorial Building,

Queens Road, Bristol BS8 1RJ, UK

Full list of author information is available at the end of the article
} 


\section{Introduction}

This is the second of two related papers ${ }^{1}$ that together investigate the interface between the scientific treatment of volcanic hazards and the governance of volcanic risks. Both papers are principally concerned with issues of risk governance and their focus is hazard communication by volcanologists at this hazard-risk interface (the interface) during periods of volcanic unrest.

Two extremes of knowledge production can be described and contrasted. Mode- 1 products have been described as conventional scholarly reflections that are driven by the motivations of their producers "to get the science right" (US/NRC 1996). Detached from both social context, and political and other values, these products seek to characterise and predict the natural world 'as it is', for a separate, sequential, downstream political management response. By contrast, Mode- 2 products are driven by the requirements of their users and strive "to get the right science". Their production and application take place through co-evolutionary processes of open dialogue between producers and users and hence these processes can be said to be processes through which the science and ultimately the actions resulting from that science are ensured to be appropriate for the social context in which they take place. This contextualisation involves methodical changes of not only scientific-knowledge outputs and outcomes (i.e. processes of communication), but also scientific-knowledge production itself.

The trial of six scientists and a government decisionmaker for involuntary manslaughter following the L'Aquila earthquake highlights the practical realities of contextualisation, the influence of multiple cultural, political, social and scientific factors before, during and after the disaster, and the complexities of risk governance regimes involving government entities at national, regional and local levels (Alexander 2010, 2013, 2014a, 2014b; Gabrielli and Di Brucci 2014). We hypothesise that this trial identified a failure of contextualisation, as we have defined above and in our first paper, and we argue that, to improve hazard communication at the interface, volcanologists need to adopt an approach that openly embraces the benefits and confronts the challenges of contextualisation.

In our first paper, we argued that the working practices of contextualisation must be more methodical and should strive to be open, transparent and fully articulated. Contextualisation that meets proposed quality assurance standards will enhance hazard assessments and, thereby, the utility of their outputs and outcomes. That utility should be framed and reviewed by reference to the sentiments and informed actions of decision-makers.

In this paper, the focus is directed away from the perceived qualities of more 'socially robust' hazard assessments towards the actual process of contextualisation itself. The four quality assurance standards that were advocated in our first paper are summarised in Table 1. In this paper, we investigate: (1) whether these four standards reflect the sentiments of practitioners at the interface: and (2) whether they can be deployed to address practical challenges. Although our focus is on volcanic risks, this approach could be applied equally to communications about other natural hazards.

\section{Methods}

\section{Assumptions and terminology}

This investigation principally concerns volcanologists in their role as volcanic hazard assessors and some of its findings are based upon data derived from them. We accept that we could have approached the same research issues by analysing data from decision makers acting in their capacity as stakeholders using scientific assessments. The decision to acquire data only from volcanologists was based upon two working hypotheses.

Firstly, while accepting evidence that a degree of informal contextualisation of hazard assessments is becoming more commonplace (e.g. Mayberry 2016; Potter et al. 2014; Jolly and Cronin 2014) we adopt as a working assumption that, in many regions with volcanic hazards, it is not common practice for volcanic hazard assessments to be 'contextualised' by any formal, methodical, documented or auditable process. Secondly, we hypothesise that the pre-communication expectations of decision-makers (i.e. in terms of the timing, scope, depth and format of information provision) are dynamic, neither unique nor universal and therefore, with limited research resources, less would be gained by investigating and attempting to characterise them at a single moment in time.

The risk governance terminology used within this paper is defined in Table 1 of our first paper and, we have deliberately avoided use of the expression "end-users" to describe decision-makers receiving science-based services. Given

Table 1 Four quality assurance standards for the processes of contextualising volcanic hazard assessments

\begin{tabular}{ll}
\hline $\begin{array}{l}\text { Standard } \\
\text { (the first three from } \\
\text { Fischhoff 2013) }\end{array}$ & Purpose \\
\hline Materiality & $\begin{array}{l}\text { To promote the paramount status of users' needs, } \\
\text { which may reflect competing demands related to } \\
\text { the speed, scope and precision of scientific advice } \\
\text { required. }\end{array}$ \\
Proximity & $\begin{array}{l}\text { To promote effective user-access to scientific } \\
\text { advice in both time and space. }\end{array}$ \\
Comprehensibility & $\begin{array}{l}\text { To ensure users can readily extract sufficient meaning } \\
\text { from scientific advice. }\end{array}$ \\
Integrity & $\begin{array}{l}\text { To nurture the willingness of users to receive and } \\
\text { trust scientific advice and make informed decisions } \\
\text { based upon the quality of existing relationships. }\end{array}$ \\
\hline
\end{tabular}


that we argue in favour of the planned and integrated contextualisation of services throughout the processes of their production and delivery, we see the term "end-users" as inadequate. Alternative expressions, such as "collaborators", "co-producers" and "partners", have other weaknesses. We also assume that, in most countries, the usual role of volcanologists is not to lead risk governance efforts, but instead to undertake hazard assessments, to contribute hazard knowledge and, if requested, related advice.

\section{Literature review and survey design/content}

A literature review was first undertaken to find historical published evidence of interface challenges.

Secondly, a survey (Additional file 1) targeted a cohort of 33 volcanologists (Additional file 2) with experience of hazard assessments derived from involvement with volcano observatories and/or relevant academic research. A minimum degree of anonymity was guaranteed by ensuring that specific responses could not be linked to identifiable individuals. Each participant has been given an identifying number and further gender, age and nationality details are summarised in Additional file 2 .

The aim of the survey was: (1) to capture a post-L'Aquila snapshot of working practices for hazard assessments and related sentiments; and (2) to reflect a range of ages, experience, hazard settings and cultures. We argue that the current practices and sentiments of the interviewees, who included many of the world's most influential leaders in the science of volcanoes, may indicate whether a more structured approach to contextualisation would find favour amongst volcanologists and, if so, what principles of contextualisation would be most acceptable. It is not suggested that the cohort was either big enough or sufficiently representative to enable assumptions to be made about results that might have been elicited from a bigger, different or more diverse cohort. It is accepted that the data may have an unintended Anglo-Saxon, Anglo-USA and/or Northern Hemisphere bias. In the absence of a larger or different cohort of participants, it is not possible to assess the nature, extent and implications of this possible bias. A future survey of volcanologists practising in, inter alia, Iceland, South-East Asia, Latin and South America, New Zealand, Japan and Africa would provide helpful complementary data.

The questions in the survey were drafted after, and based upon, our literature review, which revealed evidence that the interface is "treacherous" because "strong tensions arise", and "a neat demarcation between scientific evidence, societal values and beliefs, economic considerations and policy-decisions is not always easy" (OECD 2015, 13). This led in turn to the identification of the main components of hazard assessment and several commonly used value statements. It is not possible to attribute the genesis of each value statement to a definitive source. The sources referred to in Additional file 3 are acknowledged in respect to certain key values.

The main substantive questions considered in this study adopted the same general format, which was:

You will find below a list of possible characteristics of the [methods] of volcanic hazard assessment [processes]. Please indicate the extent to which you consider them to be important for the effective fulfilment of your usual hazard/assessment/risk management role

(Additional file 1, questions 24, 27, 30, 36, 39, 46).

The words in square brackets changed, question-by-question, to redirect the focus from say, methods of analysis, to the status of analysis, to the delivery/content/status/perception of communications or to the advice content of communications.

Since one of our goals was to measure the relative importance that hazard assessors attached to several related value statements about a common research dimension (for example values related to hazard communications) the survey used Likert scale questions (Bryman 2012).

For the substantive value statements in Questions 24, 27, 30, 33, 36 and 39 (considered in Tables 4 and 5), a 6-point range was used, the points being Irrelevant (scored -1), Unsure (scored 0), Relevant - Slightly important (scored 1), Relevant - Important (scored 2), Relevant- Highly important (scored 3) and Critical (scored 4). For the statements involving the forms of advice/guidance that may accompany hazard communications in Question 46 (considered in Table 7), a 5-point range was used, the points being Never provide (scored -1), Unsure (scored 0), Sometimes provide (scored 1), Routinely provide (scored 2) and Always provide (scored 3). It was not assumed that all the participants perceived the interval between each point in the same way.

A quantitative analysis of the scores was undertaken to produce an approximate ranking of all related value statements. In Tables 4 and 5 , the values have been ranked from highest (most important) to lowest (least important) based on the percentage of the maximum score (i.e. number of participants for each question times a maximum score of 4). The working assumption that is derived from the answers is that they give an indication of the relative importance attached to each value statement by the participating cohort of volcanologists. In Table 7, the forms of advice/guidance have been ranked from most common (always) to least common (sometimes) based on the percentage of the maximum score (i.e. number of participants for each question times a maximum score of 3 ).

For each value/form of advice, a median narrative is also provided. Although cardinal standard deviations 
were calculated, they are not set out here because it is accepted they are not of any statistical significance given the small number of survey participants.

\section{Interviews}

Eighteen one-to-one semi-structured interviews with experienced volcanologists were conducted by the first author over a period of 8 months beginning in July $2014 .^{2}$ Although the principal purpose of each interview was to complete the survey, which was used as an interview agenda to provide structure, the interviewees were encouraged, by both open and closed questions, to talk freely and in greater detail around the issues raised in the survey (Bryman 2012). The interviewees, all of whom spoke fluent English, were handed an Ethical Agreement (Additional file 4) that was signed by the first author. No interview requests were declined, and all interviews were recorded by express consent and later transcribed for detailed qualitative analysis. The interviews averaged $1 \mathrm{~h} 17 \mathrm{~min}$ in duration (shortest $38 \mathrm{~min}$; longest $2 \mathrm{~h} 6 \mathrm{~min}$ ).

The data derived from the interviews, other than the scored statements referred to above, were subjected to two forms of qualitative analysis - 'grounded theory' (Glaser and Strauss 1967, Strauss and Corbin 1998; Bryman 2012) and 'thematic analysis' (Bryman 2012).

An approach based upon grounded theory was adopted because we neither had, nor wished to use, preconceived, 'fixed' (i.e. standardised) codes "to label, separate, compile and organise data" (Charmaz 1983, 186). It is accepted that the layout and content of the survey provided a considerable degree of initial coding. The data collection (by means of the survey and interviews) and analysis proceeded in parallel. Evolving conceptual ideas and substantive theoretical arguments were developed out of the data, through an iterative approach. Within the thematic analysis, examples of initial/open coding and selective/focussed coding including axial coding were identified (Strauss and Corbin 1990; Charmaz 2006).

\section{Background - Historical evidence of interface challenges}

It is necessary to identify and characterise carefully the foreseeable practical realities faced by scientists engaged at the interface in order to help develop the more structured contextualisation that we advocate as being necessary. A literature review of published work was undertaken to find evidence of challenges faced at the interface and this revealed a rich discourse that includes some general warnings and identifies many difficulties that require further detailed consideration. Commentators, however, have thus far failed to identify common themes, and possible underlying causal trends, that might form the basis for the development of practical solutions that can be developed and tested for utility by further research.

The interface is treacherous (OECD 2015) having been described as the "science-management" interface (Jolly and Cronin 2014) delineating the demarcation between the 'factual' world of knowledge and understanding, and the 'normative' world of value. The separation of these two worlds, which clearly and inevitably interact within risk governance, is increasingly problematic, a naïve oversimplification, murky ${ }^{3}$ and somewhat contrived (Horlick-Jones 1998; Stirling 2007; Renn 2008; Donovan and Oppenheimer 2012 ${ }^{4}$; OECD 2015). The interface can create stress and friction, and become "critical and contentious" (Aspinall and Cooke 1998; Newhall et al. 1999, 2000; Metzger et al. 1999; Solana et al. 2008; Renn 2008 ; Macrae 2011; Potter et al. 2014; Pierson et al. 2014; Neuberg 2015).

The role of volcanologists at the interface appears to be poorly defined (being divisive, blurred, and porous and confused) provoking debate involving a wide range of academics and commentators from both general scientific and geo-scientific backgrounds (Peterson 1996; Nowotny 2003; Renn 2008; Ronan et al. 2000; Stirling 2010; Donovan and Oppenheimer 2012, Marzocchi et al. 2012; Donovan and Oppenheimer 2014'; Bretton et al. 2015; OECD 2015 ${ }^{7}$ ).

Our review highlights several themes involving roles, uncertainties, changes and difficulties, which we summarise in Table 2.

Demands and pressures upon volcanologists at the interface not only create anxieties and emotional responses, but also influence their behaviour and decisions. On closer investigation of the evidence presented, and the sources listed in Additional file 3, the practical realities can be identified from, and are reflected in, the types of behaviour summarised in Table 3 .

Although it is not suggested that Table 3 contains a comprehensive list of interface issues, we argue that: (1) it presents a realistic characterisation of the realities of hazard assessments; and (2) it identifies many of the foreseeable practical challenges faced by volcanic hazard assessors. The list can therefore be used to begin the identification and characterisation of some of the complex realities that quality standards for contextualisation may need to consider and attempt to mitigate.

We refer to the 'equilibrium of contextualisation' introduced in our first paper and the effect that 'stakeholder pressures' have upon it. Adopting Rothstein's model (Rothstein et al. 2006), we argued that contextualisation is in 'equilibrium' when there is 'balance' between the influences of quality standards (regulation), natural and operational constraints (reality) and stakeholder pressures (deregulation). Balance is achieved when regulatory sources are effective, quality standards are 


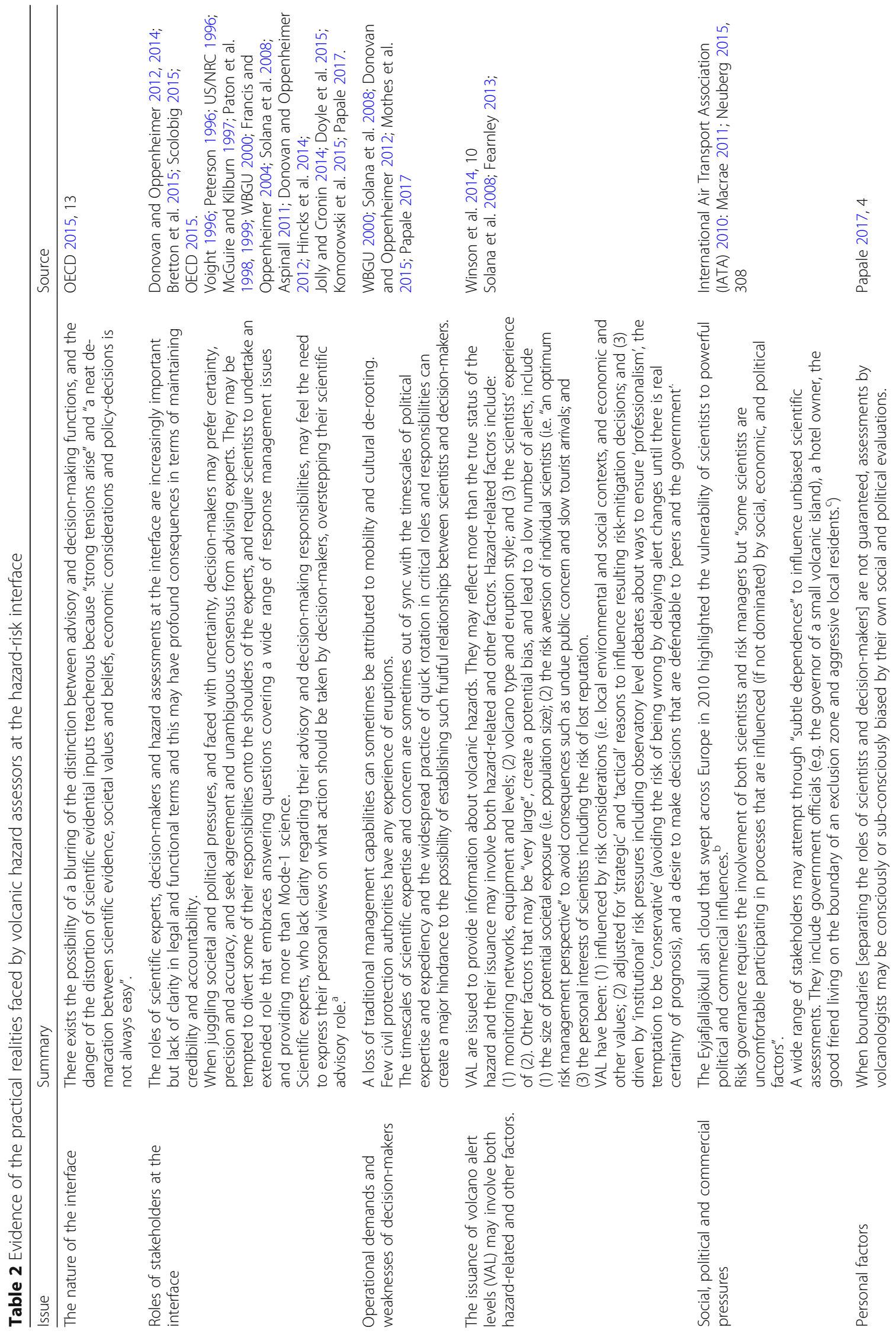




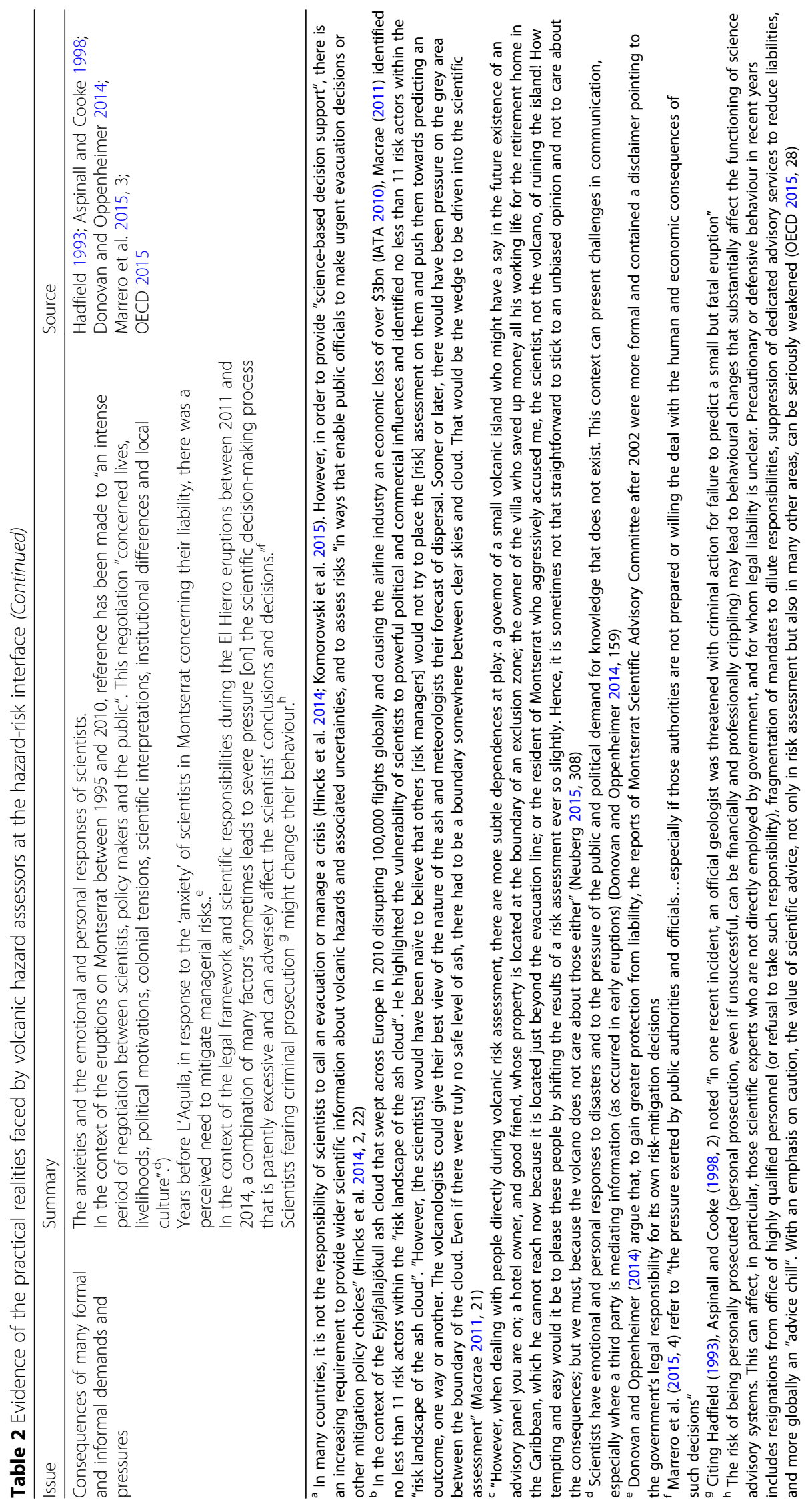


Table 3 Behaviour reflecting assessments influenced by factors not strictly confined to, or derived from, evidence-based scientific analysis of volcanic hazards, and detrimental to quality standards of integrity, materiality, comprehensibility and proximity

Behaviour detrimental to a quality standard of integrity

(1) Characterisations that:

(a) are not the product of scientific rigour and good practice;

(b) are more complete or certain than justified by the available data;

(c) do not reflect openly levels of significant scientific disagreement; or

(d) reflect psychological, personal and other subjective factors.

(2) Consideration of:

(a) societal issues such as population/valued asset exposures and vulnerabilities and thereby risk-related consequences;

(b) political, economic, local, or environmental values; or

(c) commercial, ideological, religious or local sentiments and pressures.

(3) Advocating, favouring, encouraging or refuting the views of other stakeholders on non-scientific matters.

(4) Consideration and/or choice of risk-mitigation options such as risk alert levels.

(5) Actions intended not only to inform non-scientific/risk-mitigation decisions but also to influence, directly or indirectly, their nature and/or timing.

(6) Actions that may represent breaches of duties of care owed in criminal and civil law.

(7) Blurring of functional risk governance roles involving scientific hazard analysis and risk-mitigation decisions and/or the assumption by volcanologists of another stakeholder's duty to make risk-mitigation decisions.

(8) Precautionary, defensive, conservative or blame-related bias related to perceived 'managerial' risks as opposed to 'societal' risks.

Behaviour detrimental to quality standards of materiality, comprehensibility and proximity

(9) Communications that do not respond to the needs and expectations of risk-mitigation decision-makers.

unequivocal and enforced, within natural and operational constraints stakeholder pressures are addressed, and structured contextualisation preserves scientific methodologies and probity.

The nine items listed in Table 3 represent evidence of actual and potential behaviour consistent with 'stakeholder' influences and/or some degree of informal and unstructured contextualisation. Careful characterisation of these items is important, if quality standards to safeguard values attributed to traditional scientific methodologies are going to be proposed. The first eight items in Table 3 may infringe the advocated standard of integrity. Item 9 (communications that do not respond to the needs and expectations of risk-mitigation decisions-makers) may breach Fischhoff's standards of materiality, comprehensibility and proximity (Fischhoff 2013).
This paper adopts the figure we used in our first paper which is reproduced here as Fig. 1. As illustrated in Fig. 1, the behaviour in Table 3 may create disequilibrium and imbalance, and thereby increase the possibility of a diminution in traditional standards of scientific probity.

\section{Survey of current practices and sentiments at the interface}

For the sake of clarity, the functions of 'scientific analysis', 'scientific communication' and 'scope of scientific advice' are addressed separately under sub-headings and, for the sake of brevity, lengthy verbatim quotes from interviewees are contained within end-notes.

\section{Scientific analysis}

Two questions focussed upon the analytical function undertaken by volcanologists when assessing volcanic hazards. One question (question 27) addressed the 'status' or 'nature' of some of the measurable characteristics of that function; the other (question 24) the 'methods'. Table 4 sets out the wording of the values used within the relevant questions and the words in bold are adopted hereinafter for ease of reference. This general format is also adopted in Tables 5 and 7.

Within this section, more detailed reference will only be made to those values that: (1) are of particular relevance to our consideration of quality standards for contextualisation; or (2) may provide evidence that analytical processes are undergoing changes that may lead to better hazard assessments in the future and additional scope for contextualisation.

The critical role of monitoring data was recorded, and interviewees stated the importance of acquiring historical and benchmarking data over lengthy periods and fully and carefully characterising past events. Several interviewees highlighted the values of multi-disciplinary contributions, systematic analysis and deliberation. In the context of more systematic approaches to analysis, six interviewees (Ints. 3, 4 12, 15, 19, 24) described an emerging debate about: (a) the nature of and the role for subjective judgements/contributions; (b) the utility, if any, of 'doppelganger' and 'analogue' studies; (c) the transferability of experience between hazards with different magma compositions; (d) the benefits, if any, of gravity, geo-magnetic and 'real-time' geo-chemical and petrological data; and (e) the use of bespoke research, computer models, community/local sources of knowledge and global data resources.

A link was established by two interviewees (Ints. 7, 19) between 'open and transparent' analytical processes and 'balanced,' 'written' communications capable of building 'confidence/trust'. To support this view, the rankings for the scores for these four values were very similar and relatively high, being respectively $78,78,82$ and 81 . 


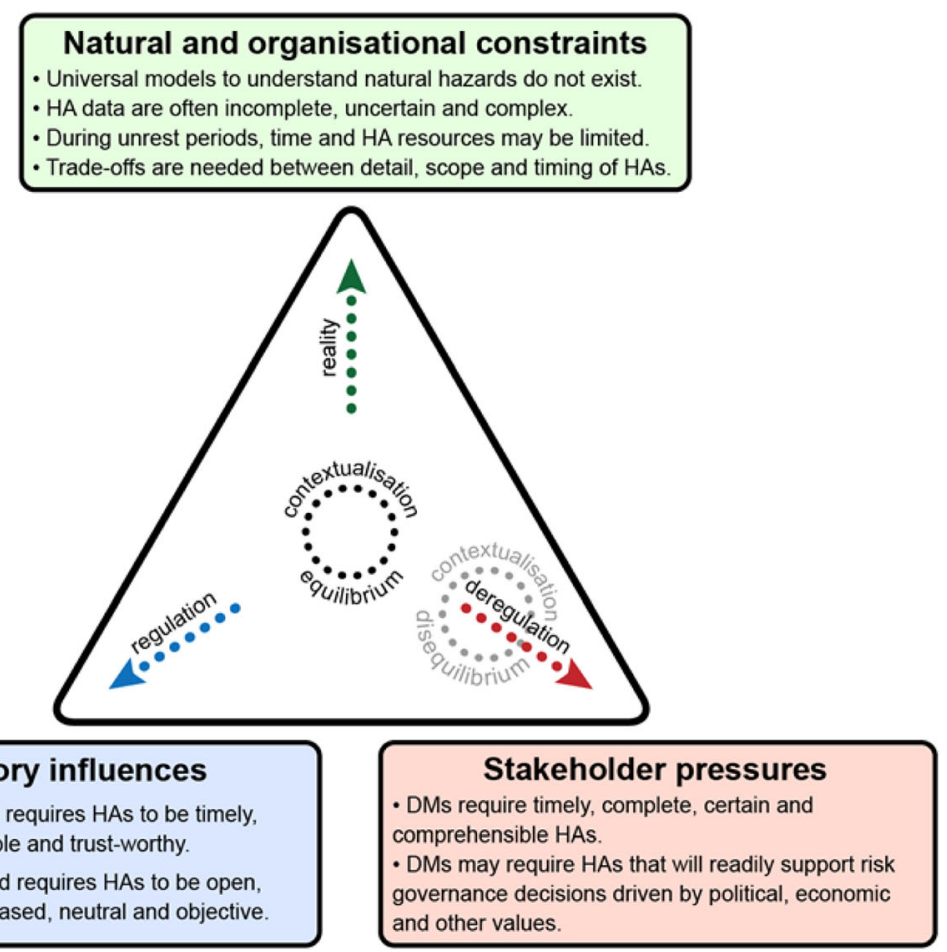

Fig. 1 Contextualisation in Equilibrium and Disequilibrium

Key: Examples of possible influences, constraints and pressures are given; Hazard Assessments (HA); Decision-makers (DM); Contextualisation is in 'equilibrium' when there is 'balance' between the influences of quality standards (regulation), natural and operational constraints (reality) and stakeholder pressures (deregulation). Balance is achieved when regulatory sources are effective, quality standards are unequivocal and enforced, within natural and operational constraints stakeholder pressures are addressed, and structured contextualisation preserves scientific methodologies and probity. Disequilibrium and imbalance may result when regulatory sources are ineffective, quality standards are equivocal or unenforced, within natural and operational constraints stakeholder pressures are not addressed, and ad hoc contextualisation fails to preserve traditional standards of scientific probity (Reproduced from Bretton et al. 2018)

\section{Scientific communication}

Four questions (questions 30, 33, 36 and 39) focussed upon the nature, perception, delivery and content of communications made by volcanologists to decision-makers. These questions were relevant to all four of our proposed quality standards.

Several interviewees said that the survey's status values relating to issues of integrity were in reality a list of 'ideals'. In the words of one (Int. 4), they are "very hard to achieve in practice and [equally] difficult to demonstrate...These are all very high standards to really achieve. I mean these are aspirations." One interviewee (Int. 19) prefaced their commentary on these characteristics by implying that these were matters upon which the recipients of hazard communications, and not the providers thereof, should comment. All these matters were relevant because each one had to be 'considered' by the provider scientists and thereafter discussed with recipient stakeholders. From their own personal experience, "There is very little discussion with the consumer about what they want". Another (Int. 3) said, "It all depends on the user". Another respondent (Int. 11) stated that their scores reflected their belief that "We need to keep it simple and clear. Too much detail on some aspects of the information can be a bad thing, as it might introduce confusion." Table 6 contains a summary of comments about the nature, delivery and perception of communications made by volcanologists to stakeholders insofar as these are relevant to quality standards for contextualisation.

\section{Scientific communication (advice scope)}

One survey question (question 46) investigated the range of advice and guidance provided by volcanologists during periods of emerging volcanic unrest. This question was relevant to, and complements, the historical evidence of a treacherous interface and the possibility that the distinction between advisory and decision-making functions might become blurred. All the values in this question, which are detailed in Table 7 , related to our proposed materiality quality standard.

Interviewee 27 prefaced all answers by stating that the nature and extent of the advice that accompanies hazard communications was "culture dependent", particularly in 
Table 4 Value statements relating to the analysis of volcanic hazards

\begin{tabular}{|c|c|c|c|}
\hline Value statement & Ranking /42 & $\%$ Max score & Median narrative \\
\hline Evidence (analysis based upon monitoring data for the volcano being assessed) & 6 & 88 & Critical \\
\hline $\begin{array}{l}\text { Multidiscipline (analysis based upon a wide range of scientific disciplines e.g. geophysics, } \\
\text { geochemistry, geodetics etc.) }\end{array}$ & 9 & 85 & Critical \\
\hline Analytical, systematic and rational process & 12 & 84 & Critical \\
\hline $\begin{array}{l}\text { Deliberation (analysis based upon the collective interdisciplinary consideration of several } \\
\text { expert views) }\end{array}$ & 13 & 83 & Very imp. \\
\hline Defensible process & 19 & 80 & Very imp. \\
\hline Documented process & 24 & 78 & Very imp. \\
\hline Open and Transparent process & 26 & 78 & Very imp. \\
\hline $\begin{array}{l}\text { Experience (analysis based upon expertise derived from knowledge of many volcanoes } \\
\text { including possible doppelgangers) }\end{array}$ & 27 & 77 & Very imp. \\
\hline Planned and Auditable process & 31 & 67 & Very imp. \\
\hline Reproducible process & 32 & 66 & Very imp. \\
\hline $\begin{array}{l}\text { Expert elicitation (analysis based upon pooled expert advice derived from some form of } \\
\text { formal expert elicitation) }\end{array}$ & 33 & 65 & Very imp. \\
\hline Quality assured/audited process & 37 & 53 & Important \\
\hline Probabilistic tools (analysis using tools such as BET_EF, HASSET, QVAST etc. ${ }^{a}$ ) & 39 & 53 & Important \\
\hline
\end{tabular}

Scoring and ranking regimes: A 6-point range was used, the points being Irrelevant (scored -1), Unsure (scored 0), Relevant - Slightly important (scored 1), Relevant - Important (scored 2), Relevant- Highly important (scored 3) and Critical (scored 4). The survey's 42 values relating to analysis and communication have been ranked in the table from highest (most important) to lowest (least important) based on the percentage of the maximum score (i.e. number of participants for each question times a maximum score of 4). Rankings not shown in this table are in Table 5 because they relate to communication rather than analysis. For each value, a median narrative is also provided

${ }^{\text {a }}$ Sandri et al. 2009; Sobradelo et al. 2014; Bartolini et al. 2013

relation to risk alert levels. Another (Int. 28) wished to emphasise the importance of long-term monitoring, even if it is only through a basic skeletal system. In addition to providing "absolutely vital" threshold data, such ongoing monitoring may also help to familiarise at-risk communities regarding hazards in a routine way and thus enable them to understand the significance of minor earthquakes and other evidence of possible unrest.

Interviewee 1 did not like 'status of volcano level' systems, believing them to be dangerous because spatial, temporal and intensity parameters cannot be pigeonholed. They did not like knowing that risk levels and risk mitigation strategies might be linked automatically to hazard levels. "I really don't like [volcano status level] systems because they are implicitly risk level [systems]. The other problem is [that] with volcanoes if you go through their status level, volcanoes often go very quiet just before they explode. They lock up. Seismicity drops, gas drops...." (Int. 1).

Issues of experience and training were raised. One interviewee thought that the provision of hazard mitigation advice depended upon the relative experience levels of the hazard and risk assessors. "I think advice should be offered...even when those who have to implement it may not have thought there is a possibility [of mitigation]." The same interviewee made the same point in relation to risk mitigation advice. "If you have the experience, you should provide it if you can, but the point is, if you don't do it, I don't think you should be found wanting...I would steer clear of [the giving of risk mitigation advice] most of the time... because [if you give it] you take responsibility for it." Interviewee 27 expressed a complementary view saying that all advice must be sound and within the bounds of the adviser's "mandate and expertise".

Interviewee 11 volunteered " $[\mathrm{m}] \mathrm{y}$ scores reflect my training...We work on hazards, not risk. Risk is the domain of other organisations we work with, so we should leave that to the experts...until that becomes something we work on ourselves." This response directly raised the issue of the existence and nature of the interface and the way in which this interface determines roles and vice versa.

\section{Discussion of current practices and sentiments at the interface}

The results presented in the last section are now discussed with reference to our proposed quality standards.

\section{Quality standard - integrity}

Many of the results are directly relevant to this proposed standard which goes to the very heart of the way in which the analysis of volcanic hazards is undertaken. Although current methodologies and processes of analysis are often neither structured nor recorded in a formal way (i.e. they are not 'protocolised' and remain largely undocumented), there is clearly a high degree of 
Table 5 Values related to the nature, perception, delivery and content of communications

\begin{tabular}{|c|c|c|c|c|}
\hline Value statement & Ranking /42 & $\%$ Max score & Median Narrative & Standard \\
\hline Timely delivery (reflecting the dynamic demands of the situation) & 1 & 92 & Critical & Prox. \\
\hline $\begin{array}{l}\text { Independent (free from duress and uninfluenced by the pressures of all } \\
\text { affected and interested parties) }\end{array}$ & 2 & 91 & Critical & Integ. \\
\hline Free from the influence of commercial interests & 3 & 91 & Critical & Integ. \\
\hline Non-political & 4 & 90 & Critical & Integ. \\
\hline Honest and candid (even if worrisome) & 5 & 89 & Critical & Integ. \\
\hline $\begin{array}{l}\text { Neutral/Unbiased (free from institutional systemic bias, which tends to } \\
\text { encourage particular outcomes, and not advocating, encouraging or } \\
\text { refuting any stakeholder view/risk management action) }\end{array}$ & 7 & 86 & Critical & Integ. \\
\hline Delivered from one authorised source (to avoid mixed scientific messages) & 8 & 86 & Critical & Prox. \\
\hline Free from the influence of ideological and religious interests & 10 & 85 & Critical & Integ. \\
\hline $\begin{array}{l}\text { Recipient centric - "User-friendly" (directed to the identified } \\
\text { needs/wishes/uses of the recipients and to enable them to make } \\
\text { "informed" choices) }\end{array}$ & 11 & 84 & Critical & Mat. \\
\hline Written & 14 & 82 & Critical & Prox. \\
\hline Likelihood (probability of onset of defined scenario) Clarity & 15 & 82 & Critical & Comp. \\
\hline $\begin{array}{l}\text { Understandable/unambiguous terminology } \\
\text { (geological, chemical, scientific and qualitative terms) }\end{array}$ & 16 & 82 & Critical & Comp. \\
\hline Confidence/Trust building & 17 & 81 & Critical & Integ. \\
\hline $\begin{array}{l}\text { Outcome/Output centric (relevant to subsequent risk management } \\
\text { processes and decisions) }\end{array}$ & 18 & 80 & Critical & Mat. \\
\hline $\begin{array}{l}\text { Value-free (unaffected by societal context e.g. knowledge of societal } \\
\text { exposures and vulnerabilities) }\end{array}$ & 20 & 79 & Very imp. & Integ. \\
\hline Objective (removing as much subjectivity as possible) & 21 & 79 & Very imp. & Integ. \\
\hline Authoritative & 22 & 79 & Very imp. & Integ. \\
\hline $\begin{array}{l}\text { Balanced (reflecting unknowns, uncertainties and the range of } \\
\text { differing expert views) }\end{array}$ & 23 & 78 & Very imp. & Integ. \\
\hline Reflecting current scientific "Good Practice" & 27 & 76 & Very imp. & Integ. \\
\hline Assumptions, limitations, time/cost constraints, etc. Clarity & 28 & 75 & Very imp. & Comp. \\
\hline $\begin{array}{l}\text { Confidence (variability due to limited/lack of knowledge, etc. reflected } \\
\text { in the width of the } 95 \% \text { confidence interval) in Likelihood Clarity }\end{array}$ & 29 & 72 & Very imp. & Comp. \\
\hline $\begin{array}{l}\text { Graphics (such as pie charts, histograms, event trees, etc.) to } \\
\text { illustrate/support narrative }\end{array}$ & 30 & 67 & Very imp. & Comp. \\
\hline $\begin{array}{l}\text { Likelihood Expression in qualitative terms (e.g. "likely") as well } \\
\text { as quantitative terms (65\%) }\end{array}$ & 34 & 58 & Important & Comp. \\
\hline Tweets, public internet status alerts, etc. & 35 & 54 & Important & Prox. \\
\hline $\begin{array}{l}\text { Peer reviewed (to the extent possible given the dynamics } \\
\text { of the situation) }\end{array}$ & 36 & 53 & Important & Integ. \\
\hline Confidence Precision & 38 & 53 & Important & Comp. \\
\hline $\begin{array}{l}\text { Confidence Expression in qualitative terms } \\
\text { (e.g. "high/medium/low confidence") or a probability range } \\
\text { (e.g. 65-75\%) reflecting the width of the confidence interval }\end{array}$ & 40 & 51 & Important & Comp. \\
\hline Likelihood Precision & 41 & 48 & Important & Comp. \\
\hline Provider centric (directed to the needs/wishes of the hazard assessors) & 42 & 28 & Important & Comp. \\
\hline
\end{tabular}

Scoring and ranking regimes: A 6-point range was used, the points being Irrelevant (scored -1), Unsure (scored 0), Relevant - Slightly important (scored 1), Relevant - Important (scored 2), Relevant- Highly important (scored 3) and Critical (scored 4). The survey's 42 values relating to analysis and communication have been ranked in the table from highest (most important) to lowest (least important) based on the percentage of the maximum score (i.e. number of participants for each question times a maximum score of 4). Rankings not shown in this table are in Table 4 because they relate to analysis rather than communication. For each value, a median narrative is also provided Values related to the proposed integrity standard (Integ.) are in shaded rows

Abbreviations: Median narrative - Very important (Very imp.); Quality standards - Proximity (Prox.), Integrity (Integ.), Materiality (Mat.) and Comprehensibility (Comp.) 
Table 6 A summary of comments about the nature, perception, and delivery of communications made by volcanologists to end-users relevant to quality standards for contextualisation

\begin{tabular}{|c|c|}
\hline Value & Summary of comments (interviewee reference) \\
\hline $\begin{array}{l}\text { Independent, neutral, } \\
\text { objective }\end{array}$ & $\begin{array}{l}\text { These are wonderful ideals/aspirations worthy of pursuit. They are difficult to achieve in practice and demonstrate objectively } \\
(4,15,27) \text {. } \\
\text { They can easily be lost by individuals being 'welded' by training and/or practice to certain conceptual or theoretical models (15). } \\
\text { Expert elicitation processes can assist objectivity "because the big cheeses cannot just override the other people who might } \\
\text { have very good arguments" (15) }\end{array}$ \\
\hline
\end{tabular}

Neutral, Value-free, Recipient/Outcome centric

Balance

Understandable

Good practice

Peer review

Provider centric

Confidence/Trust building

Delivery -Timely, one source, authoritative

Written

Graphics and scientific terminology

Clarity, precision and confidence
There are occasions when value free neutrality is not possible and appropriate, and it is better to nuance volcano level changes to produce an apparent gradual escalation of unrest with the objective of assisting risk managers and preventing unnecessary public alarm (28).

Societal context should not influence hazard analysis at all $(12,17)$

If analytical processes are always constrained by time, resources etc., they should be focussed on selected areas based upon any acquired knowledge of 'exposure' and 'vulnerability' risk variables $(12,19,24)$

Analytical processes cannot ignore context as scientists must be realistic and recipient-focussed. Scientists must act in a way that helps risk decision makers make informed decisions (3).

A hazard assessment merely starts a conversation with other stakeholders (19).

Commercial, ideological and religious interests cannot be ignored if scientists are to be truly recipient focussed (24).

"You can't ignore them [commercial interests] nor can you...completely detach from the political system in which you're operating because... there are going to be political realities which constrain what you can do and... there are going to be practical compromises one comes to because otherwise your advice is going to get ignored so you can't afford to be too prissy" (4).

It is important to record and communicate not only the view of the majority but also the opinions of dissenters $(15,28)$.

Communications must be recipient focussed, in content and form, and respectful of distinct cultural/community contexts $(1,10,19)$

This issue is not straightforward because it raises the complex issue of quality - in particular, values and thresholds for practice quality and practitioner competence.

Views were expressed that quality of practice is: (1) context dependent; (2) dynamic, as it evolves as a function of time; (3) linked to the values of openness and transparency; and (4) related to stakeholder trust.

Obvious practical difficulties arise during emergencies, but PR would be more practical if one separated the information being used (the data, analysis, models, etc.) from the advice-giving process itself.

It is important to differentiate between supplementing the expertise/experience of one group of advisers by the informal means of using external competent resources (e.g. a review or second opinion by email or by phone) and true formal PR by independent anonymous reviewers (4).

Recipients are annoyed by words in communications that are included merely "to cover" the scientists providing analysis (24). At worst this approach is "this is my programme [meaning in this context analysis], this is what it produces, take it or leave it" (1)

Trust must be built and, once built, you don't need to worry about it. It can be built by listening to, and working closely with, interested communities and, in particular, commercial and religious stakeholders (24).

It comes from 'dialogue' and it is important to have direct communication with religious, commercial and political communities about what 'impartial' scientific analysis meant "in their context" (24).

Trust may be linked to 'independence'. "Independence from... local government is absolutely critical because... [it] is related to trust... If the scientists are increasingly seen as an instrument of government, the trust they have as being independent is... dissipated" (15).

"I think that the legal pressure after the L'Aquila trial urged us a lot to write down best practice" (Int. 14).

Sometimes, irrevocable deadlines, which were unnecessary or unreasonable, were imposed and adhered to. Often "a degree of flexibility" would permit something less "half-baked or incomplete" and with less "mistakes" (4)

One source is not always the correct approach. "There are a lot of people saying...there should only be one view, one version. I think that is to underestimate the intelligence of politicians in the public eye. It avoids conflict. It avoids ambiguities but sometimes [more than one source] can serve a purpose". They opined that, if there are truly two differing schools of thought, expressing them through a sole source may "not necessarily" be the correct way (1).

A 'written' communication is important for multiple reasons. The reasons that emerged were (1) to assist openness and transparency; (2) to assist auditing; (3) to prevent misunderstandings and misquotations; and (4) to assist proof of delivery.

The use of graphics provoked a range of views. Whilst some favoured a range of communication forms, including graphics, most the participants accepted that much depended upon the utility attached to graphics by those who receive them. Terminology "should be as simple and straightforward as possible. You can convey a very complex geological argument using very simple [terms]." (12). Glossaries of the most important volcanic and scientific terms have been used successfully. Continued and frequent use of correct geological terms is important but further relationships will assist inculcation (1).

'Clarity' of expressions regarding the likelihood of hazard onset was more important than their 'precision'. One interviewee (Int. 9) commented, "Once it [the likelihood of hazard onset] is over the threshold, it [precision] is less important". One interviewee (28) referred to the fine-tuning of precision (the difference between a $65 \%$ and $67 \%$ chance of a volcanic hazard onset) and added, "Who cares?" Another (12) stated, "Who cares. It does not matter... [fine-tuning] is meaningless. It's easy to get bogged down in these things." 
Table 6 A summary of comments about the nature, perception, and delivery of communications made by volcanologists to end-users relevant to quality standards for contextualisation (Continued)

Value
Summary of comments (interviewee reference)
used without any qualitative narrative. At the other extreme, all expressions (numbers and/or narrative) should be user-focussed
and any narrative expressions should be very carefully defined reflecting the different requirements of different audiences.
Sometimes locally-calibrated risk analogues are useful. Even the use of words of common usage may be challenging since
sometimes common words are used by scientists in a very narrow and technical way.
Confidence (i.e. variability due to limited/lack of knowledge, etc.) was linked by one interviewee with the qualities of
'openness and transparency', 'written' format and 'balanced' content. For others, this difficult concept directly impacted on
trust and, accordingly, a recipient focussed approach was needed to reflect cultural and other issues, particularly if qualitative
expressions were to be used. The reasons for doing so included: (1) to avoid giving false hope; (2) to identify issues related to
resource constraints; (3) to mitigate managerial risks by providing back coverage; (4) to build trust based upon transparency and
openness; and (5) to reflect both the quantity and quality of the available evidence.

Tweets

The use of tweets and similar modes of communication provoked a wide range of observations. Some participants warned of unintended over-reactions and consequences, and perceived difficulties of orderly coordination and recipient targeting. Others recognised that a wide range of communication recipient-focussed methods (including highly visual methods, 3D models and videos, and public talks) must be considered and that in some locations and cultures, but by no means all, social media was already very important.

*The authors readily acknowledge that social media practices have greatly advanced since the survey and interviews were conducted.

consensus as to how analysis should be undertaken. None of the values carefully selected for inclusion in the survey was 'irrelevant' or less than 'important', and no alternative or additional values emerged during the survey and interviews despite active prompting (see survey questions 26, 29, 32, 35, 38 and 41).

Survey participants favoured analysis based upon: (1) the monitoring of data for the volcano being assessed; (2) a wide range of scientific disciplines; (3) a collective inter-disciplinary consideration of several expert views; and (4) expertise derived from knowledge of many volcanoes. In the context of an apparently favoured transition to a less ad hoc and more methodical approach to contextualisation, we noted that, unsurprisingly, participants rated as either 'critical' or 'very important' a systematic and rational, defensible, documented, open and transparent process.

Current practices and sentiments may indicate whether a more structured approach to analysis would find favour amongst volcanologists and, if yes, what principles of contextualisation would be most acceptable. In this regard, survey participants clearly expressed a continuing need to separate hazard analysis (the physical dimension of risk) from risk-related influences (the societal and managerial dimensions). This was evidenced by values that emphasised the need for analysis to be non-political and free from commercial, ideological and religious influences. The demarcation is also illustrated by the apparent reluctance of hazard analysts to offer

Table 7 The range of advice/guidance provided by volcanologists during periods of emerging volcanic unrest

\begin{tabular}{|c|c|c|c|c|}
\hline The nature of the advice/guidance given by volcanologists & $\mathrm{H} / \mathrm{R}$ & Max \% score & Ranking /9 & $\begin{array}{l}\text { Median } \\
\text { narrative }\end{array}$ \\
\hline 'Status of the volcano' level (levels of hazard only) & $\mathrm{H}$ & 75 & 1 & Always \\
\hline Possible medium-/long-term evolution of the current unrest event & $\mathrm{H}$ & 75 & 2 & Routinely \\
\hline Benefits of short-term monitoring (monitoring the present by human surveillance and instruments) & $\mathrm{H}$ & 73 & 3 & Routinely \\
\hline $\begin{array}{l}\text { Safety of continued 'short-term' monitoring (e.g. the collection of samples, the placement } \\
\text { or maintenance of equipment etc.) }\end{array}$ & $\mathrm{H}$ & 60 & 4 & Routinely \\
\hline $\begin{array}{l}\text { Adequacy of 'long-term' monitoring (understanding the past from historical data, } \\
\text { geology mapping etc.) }\end{array}$ & $\mathrm{H}$ & 57 & 5 & Routinely \\
\hline $\begin{array}{l}\text { Secondary hazards (e.g. drinking water aquifers being contaminated by degassing/magma; } \\
\text { forest fires) }\end{array}$ & $\mathrm{H}$ & 54 & 6 & Routinely \\
\hline Possible measures to mitigate risks (managing the future) & $\mathrm{R}$ & 25 & 7 & Sometimes \\
\hline $\begin{array}{l}\text { Possible measures to mitigate the spatial or physical parameters of possible hazards } \\
\text { (e.g. barriers, channels, retention basins, lake drainage, water spraying, re-vegetation etc.) }\end{array}$ & $\mathrm{R}$ & 23 & 8 & Sometimes \\
\hline Risk Alert levels (levels linking the current state of the volcano to pre-determined risk mitigation actions) & $\mathrm{R}$ & 14 & 9 & Sometimes \\
\hline
\end{tabular}


mitigation advice routinely in respect of risk and hazard mitigation actions, and risk alert levels.

Consistent with this demarcation, the survey also reaffirmed the significance of the 'traditional' qualities of scientific independence, ${ }^{8}$ neutrality, freedom from value, balance and objectivity, whilst also rating highly the 'new' influences of purpose (i.e. recipient/outcome focus) and objective quality (i.e. good practice). It is noted here that these values were considered by some of the interviewees to be no more than ideals incapable of either demonstration or evaluation. Future research should consider these understandable reservations and investigate whether qualitative norms of 'good science' have any utility.

Some values that are relevant to integrity attracted relatively low rankings. There is less support for 'planned and auditable,' 'reproducible,' 'peer-review' and 'quality assured/ audited' processes which all had lower quartile rankings. The merits and practicalities of 'peer review' generated considerable debate and this may be unsurprising given the almost total absence of academic commentary on its role in the context of hazard assessments. ${ }^{9}$

The 'traditional' and 'new' values, referred to above, may represent a basis for: (1) the quality assurance steps scientists must take "to ensure the reproducibility of their analysis and the quality of their advice" (OECD 2015, 21); and (2) the rules of engagement that provide the "foundation on which scientists and risk decision-makers should base their operations and interactions", as advocated by the UK's Government Office for Science (UK/GOS 2011, 32); and the "rigorous, replicable methods" of analysis referred to in the 1996 US/NRC report (US/NRC 1996). ${ }^{10}$

\section{Quality standard - materiality}

There are new data to support the conclusion that we reached in our first paper. We concluded that there is a slow-moving paradigm shift away from a traditional linear one-way educational approach to communication towards a more iterative two-way 'outcome-focussed' dialogue with user decision-makers. The rankings that support this are the lowest possible ranking for 'provider centric' and upper quartile rankings for 'recipient centric' and 'outcome/output centric'.

There was a clear rejection of the 'provider centric' traits that are inherent features of hazard assessments that initiate traditional linear models of risk management. Whilst describing the need for hazard assessments to be 'recipient-centric', several of the interviewees described the hallmarks of contextualisation without actually using that word; i.e. they acknowledged the existence of the managerial dimension of risk governance and a need to consider the requirements of decision-makers.

Another theme, which is related to and flows from a shift towards some degree of contextualisation, is the evolving acceptance of the value of, and the need for, 'deliberation' during hazard assessments. This is evidenced by:

- the upper quartile rankings for 'deliberation', 'recipient-centric' and 'outcome-centric' communications;

- the middle quartile rankings of values expressly or implicitly supporting or encouraging a two-way dialogue with decision-makers such as openness and transparency;

- the ranking of 'clarity' above 'precision' for statements of likelihood (Score 82\%, Ranking of $15 / 42$ against $48 \%, 41 / 42)$ and for statements of scientific confidence $(72 \%, 29 / 42$ against $53 \%$, 38/42); and

- the importance attached by some interviewees to understanding commercial, religious and ideological interests whilst simultaneously maintaining their objective independence from them.

\section{Quality standard - Comprehensibility}

The choice of narrative and the use of numerical and graphical content in order to make communications understandable remains a significant challenge but there seems to be agreement about the prioritisation of issues for further discussion and research. Providing analytical 'clarity' to users is more important than analytical 'precision' as evidenced by the respective scores for likelihood clarity (82\%) and likelihood precision (48\%). Comparable results were obtained for expressions of confidence (variability due to epistemic/aleatory uncertainties) for which the comparable scores were clarity $(72 \%)$ and precision (53\%).

There remains an unresolved debate about the use of narratives to support numerical expressions of likelihood and confidence as reflected in the lowest quartile rankings for the use of qualitative as well as quantitative terms for expressions of hazard 'likelihood' and scientific 'confidence'. These two values produced some of the largest spreads of opinion and this is consistent with an ongoing discourse that has been joined by commentators such as Cooke (2015) who note the near-impossibility of devising meaningful qualitative narratives to describe numerical probabilities.

\section{Quality standard - proximity}

Practitioners at the interface know, and already attach significant importance to, the many factors that contribute to effective provider-centric communications. When the value statements for 'scientific analysis' and 'communication' are ranked together, 11 out of the top 15 related to communication. 
The participants ranked highly communications "delivered from one source to avoid mixed scientific messages" and thereby difficulties such as those experienced in Guadeloupe in 1976 (Fiske 1984). This result is consistent with the generally accepted view that authoritative scientific information and advice should be sourced through a coordinating person or body (Fiske 1984; Newhall and Punongbayan 1996; Lipshitz et al. 2001; Driedger et al. 2008; NZ/MCDEM 2008; Barclay et al. 2008; Frenzen and Matarrese 2008; OECD 2015). Doyle et al. (2015) note that this approach also facilitates the integration of the wide range of expert opinions required to manage uncertainty during decision-making and helps combat issues arising from any conflicts between scientists.

\section{Recommendations}

\section{Clearer goals for hazard assessments at the interface}

The interface role of volcanologists is either changing or, at least, is likely to change. Our literature review revealed that an increasingly wide range of services is sought from volcanologists. Consistent with this, and based on new data presented in Table 6, we have concluded that bare characterisations of the temporal, spatial and physical parameters of volcanic hazard scenarios are 'often' accompanied by advice, and that advice 'sometimes' includes advice about hazard and risk mitigation issues.

These changes are potentially significant and have foreseeable consequences (Weinberg 1972, 1992; Nowotny 2003; Van Nuffelen 2004). Volcanologists are exposed to new managerial hazards and are vulnerable to managerial risks, when they stray from their traditional roles and practices (e.g. providing lahar hazard zone maps) into an extended role (e.g. providing risk-related advice such as risk alert levels based upon lahar hazard zones). The 'exposure' comes from volcanologists extending their scientific advisory roles; the 'vulnerability' is derived from any lack of competence, time or resources to fulfil those extended and more complex roles (OECD 2015; Bretton et al. 2015; Bretton and Aspinall 2017).

With a view to assessing management risk exposures and vulnerabilities, a starting point is to define 'scientific analysis' by reference to the relevant qualities of the reasonably competent volcanologist engaged to undertake monitoring and analysis. These qualities include education, training, expertise, experience, skills and knowledge. This definition is adopted to characterise the usual role and thereby the usual exposures and vulnerabilities of volcanologists. It is argued here that caution must be exercised when scientists either volunteer or are required to adopt an extended role that includes making judgements that are not based upon the 'scientific analysis' of monitoring data, without acquiring relevant extended competencies in advance. The dangers of role extensions and poor communication were well illustrated by Simoncini (2014) in the context of the L'Aquila trial. ${ }^{11}$

In our first paper, we investigated the discourse that argues that contextualisation undertaken by scientists must be constrained within certain boundaries. To address an absence of guidance for managing these boundaries, we advocated a more structured approach based upon open, transparent and fully articulated quality standards of materiality, proximity, comprehensibility and integrity. To convey the purpose of a more structured approach, we here recommend the setting of three overriding interface goals.

Building upon the terminology of the US/NRC (1996) and Nowotny (2003), these interface goals might be:

- To identify, articulate and preserve the essential values and methodologies of 'reliable' or 'good' science - Getting assessments right, by preserving 'good science'.

- To seek out the requirements of decision-makers in a proactive iterative way so as to help ensure hazard assessments are relevant to, and fit for, their needs and expectations - Identifying which assessments will have greatest validity and utility, by means of deliberation.

- To ensure hazard analyses are not only right (i.e. reliable or good) but also socially robust (i.e. valid and relevant) - Getting the right assessments, by means of informed contextualisation.

We argue that there is neither a necessary nor an insurmountable conflict between these three goals if the principles of hazard assessment at the interface are fully articulated with an elevated level of transparency and are continually tested as advocated by Nowotny (2003) and the OECD (2015).

\section{A structured, fully articulated and integrated role for deliberation}

Deliberation has a pivotal role as the precursor to, and driver of, contextualisation. ${ }^{12}$ For deliberation to be meaningful, we argue that decision-makers must:

- have an enforceable right to seek and receive such information and training as is necessary to enable to them participate fully and effectively, and

- be given every opportunity to identify and make known: (a) the essential characteristics of scientific analysis (i.e. scientific methodology) that they value; and (b) their wider risk-related hazard assessment requirements. 
There must also be a "structured requirement that others listen" Grabill and Simmons (1998, 427).

Deliberation will drive not only the 'creation' and 'evolution' of the negotiated quality standards required to regulate contextualisation and enhance its utility, but also 'evaluations' of those standards. In the future, deliberation will be a more integral part of scientific analysis (a tail that wags the analytical dog) and not just a social science afterthought (a wagging flexible tail grafted onto the end of an inflexible linear process of analysis).

Although we fully accept that effective dialogue may be very difficult to achieve in practice, the very process of deliberation itself, which would be described by some commentators as a process of 'co-production' (e.g. Scolobig et al. 2014), may contribute to: (1) a shift of emphasis from 'individual' to 'collective' perspectives (Doyle et al. 2015 ${ }^{13}$ ); (2) the building of trust between scientists and decision-makers; and thereby (3) better riskmitigation outcomes (Hincks et al. 2014; Fischhoff 2013).

We are not attempting to supplement the established discourse describing the difficulties of undertaking volcanic hazard assessments. Rather, we are advocating new initiatives that encourage the trial of practical solutions for those difficulties based on structured deliberation with decision-makers. Four sub-questions within question 70 of our survey asked the participants to state whether, within the volcanic settings best known to them, they saw any evidence of a trend in recent years towards more public participation in hazard monitoring and assessment and risk assessment, management and mitigation. Whilst participants recorded little public participation in providing knowledge for hazard assessments (only 2 participants out of 24) and making risk assessments (2/24), more participation but still very low participation was noted in respect of hazard monitoring $(5 / 24)$ and risk management including the selection of mitigation strategies and measures (6/24). Accordingly, deliberation may have to be given a higher priority before it fulfils its potential within volcanic risk governance.

\section{More structured contextualisation}

We argue that it is possible to begin to formulate some general principles that might lead to hazard assessments with greater utility. Fine-tuning methodologies of contextualisation is both unnecessary, and inappropriate for three main reasons.

First, at a location-specific level, acceptable contextualisation practices should always be the product of structured deliberation involving relevant decision-makers. Secondly, acceptable contextualisation practices will reflect a very wide range of geological, geographical, technical, historical, governmental (at multiple levels), cultural, spiritual, linguistic, legal, political, economic, time and resource drivers (management drivers) (Bretton et al. 2015). Thirdly, scientists should consider carefully, and have appropriate regard to, the human rights of individuals, and the democratic and legal mandates, if any, of civil protection authorities, to take risk decisions based upon a wide range of factors (UK/GOS 2011). Individuals will have a variety of reasons for living with volcanic risks. Scientists should accept that a more informed understanding of volcanic hazards, to which they will make an essential evidenced-based contribution, will represent only part of the knowledge upon which difficult risk decisions will be made. Those decisions may address risks from multiple natural and human-made hazards, and reflect "structural constraints rooted in difficulty in accessing resources, historical and cultural heritage and political-economy" (Gaillard 2008, 325). ${ }^{14}$

It follows that acceptable practices (supported by evidence-based regional guidance) in one volcanic region may differ markedly from the acceptable practices in other regions. We argue, however, that all principles, values and methodologies that are widely recognised as critical hallmarks of 'good science', should be accepted as paramount and non-negotiable quality standards (i.e. a constant) in every region.

Thirdly, contextualisation is inherently 'dynamic' because volcanic hazards and risks (and related management drivers) emerge and change over a wide array of time-scales ranging from minutes and hours during periods of unrest; to weeks, months or even years during cycles of risk governance.

In Table 8, we present several general principles, firstly for further consideration and development at a location-specific level, and, secondly as a reasoned starting point for future empirical research, particularly in Iceland, South-East Asia, Latin and South America, New Zealand, Japan and Africa. These important volcanic regions will have multiple management drivers that may not be adequately addressed by our theoretical choices and the new, but limited, survey and interview data presented in this paper. Any principles relating to integrity should strive to mitigate the first eight characterisations of behaviour listed in Table 3.

We argue that a more structured, but carefully nuanced, approach to contextualisation reflecting location-specific management drivers will:

- Enhance the governance of societal risks (i.e. promote "getting better" Bretton et al. 2015, 17-18), by giving much needed clarity to:

- the treacherous, increasingly problematic and murky hazard/risk interface; and

- the divisive, blurred, porous and confused role of interface volcanologists. 
Table 8 Prototype Code of Practice and guidance for volcanic hazard assessments

Prototype Code of Practice and guidance for volcanic hazard assessments

This code:

- contains practical advice on how to provide effective outcome-focused hazard assessments;

- is not intended to be either prescriptive or comprehensive; and deliberately avoids do's and don'ts

- does not purport to have legal status but aims to assist relevant risk governance stakeholders to identify, and comply with, their legal duties; and

- can also be used as a simple, short, targeted checklist to encourage, and facilitate, deliberation between risk governance stakeholders, so that a wide range of management drivers are openly identified and discussed. These drivers may be geological, geographical, technical, historical, governmental (at multiple levels), cultural, spiritual, linguistic, legal, political, economic, or time/resource related.

Column 1 contains a code of general principles of acceptable practice that are supplemented and supported by evidence-based guidance in column 2.

\section{General principles}

Hazard assessments

Unless alternative principles are discussed and agreed with users in advance, hazard assessments shall be:

Open and transparent

Systematic, rational and capable of independent review/audit
Conducted in a manner that it is open, iterative, inclusive and understandable and thereby capable of inspiring trust in and support from end-users.

Ensuring suitable and sufficient planned assessment of all available evidence and significant issues and adequate consideration of any matter arising from legitimate and responsible scientific disagreement. Scientific disagreement and resulting communication difficulties were evident during the volcanic incidents in Guadeloupe (1976) and St Vincent (1979).

Based on relevant evidence and experience and reflect structured deliberation by experts with an appropriate range of different and complementary geo-scientific skills

Independent

Neutral

Unbiased

Value-free

Objective
A Bayesian evidentiary analysis approach may provide a way to pool imprecise judgements in the light of multiple streams of inexact data and indistinct observations. It may also provide an impartial quantitative basis for incorporating imperfect volcanological insights into hazard assessment in a coherent manner despite deterministic insufficiency.

Free from duress and uninfluenced by the pressures of other interested parties such as, but not limited to, risk decision makers, local advisers or members of the public (social pressure), the media and/or possible or actual litigation.

Avoiding advocating, encouraging or refuting the point of view of an interested party or a particular risk management response, avoiding value-laden statements and maintaining political neutrality and attempting to neutralise any unintended negative bias.

Dispassionately ignoring all "non-hazard" implications (i.e. risk assessment and management issues) that may be contingent upon the temporal, spatial and physical parameters of the hazard scenarios - i.e. framed "irrespective of the consequences of the threatening event"

Unaffected by societal context e.g. knowledge of societal exposures and vulnerabilities.

No hazard assessment can be truly objective, but the known sources of subjectivity can be stated so that they are explicit and can be challenged e.g. adopted assumptions, definitions, models, methods, thresholds, parameters, monitoring choices, etc.
US/NRC 1996; Marzocchi et al. 2012; Hill et al. 2013; Hincks et al. 2014; OECD 2015.

Fiske 1984; Driedger et al. 2008, 505; Frenzen and Matarrese 2008). See also Funtowicz and Ravetz 1992; Laudan 1996; Bruijn and ten Heuvelhof 1999; Lupton 1999; Jasanoff 2002; Merz and Thieken 2005; Renn 2008; Mellor 2008; Johnson and Jeunemaitre 2011; Spieghalter and Reisch 2011; Aspinall 2012; Marzocchi et al. 2012; Aspinall and Cooke 2013; Rougier 2013; Rougier and Beven 2013; Hicks et al. 2013; Cornell and Jackson 2013; Freer et al. 2013; Beven et al. 2015

Stern and Fineberg 1996; Renn 2008; Aspinall 2012;

Voight 1998

Kahneman and Tversky 1979; Stern and Fineberg 1996; Newhall and Punongbayan 1996; Punongbayan et al. 1996; Marzocchi et al. 2012.

Barberi and Carapezza 1996; Punongbayan et al. 1996.

Barberi and Carapezza 1996; Punongbayan et al. 1996.

Stern and Fineberg 1996; Freudenburg 1988; Bohnenblust and Slovic 1998, 159; Horlick-Jones 1998; Funtowicz and Ravetz 1990; Wynne 1992; IRGC 2005; Renn 2008; Aspinall 2012; Marzocchi and Bebbington 2012; Marzocchi et al. 2012; Leonard et al. 2014; Beven et al. 2015. 
Table 8 Prototype Code of Practice and guidance for volcanic hazard assessments (Continued)

Balanced
heflecting the inherent complexities of volcanic
and all material matters (such the absence of
available data) including those matters that may
detract from the final advice - to reflect the full
range of opinions and competing contrary views
and never cherry-picking.

In compliance with good practice and all relevant quality standards.

As far as reasonably practicable, hazard assessments shall be suitable for the purposes for which they are provided.
Identify the current dynamic standards of monitoring, analysis and communication that a reasonably competent hazard assessment would reach having complied with all applicable standards.

A hazard assessment should retain those practice values touching probity and quality associated with

A hazard assessment is suitable if it satisfies the reasonable needs of its foreseeable users. traditional scientific methodologies.
Newhall and Punongbayan 1996; Department of

Farming and Rural Affairs DEFRA - The Central Science Laboratory 2007; Marzocchi and Bebbington 2012;

Stein and Geller 2012; Rougier and Beven 2013, Stein and Friedrich 2014; Beven et al. 2015; Marti 2015.

\section{Hazard communications}

Unless alternative principles are discussed and agreed with users in advance, as far as reasonably practicable hazard communications shall be:

Candid and truthful even

if worrisome

Material

Comprehensible

Timely

Recorded in a permanent format

Easily accessible (if appropriate, delivered in a variety of formats).

Issued from one authorised authoritative source.

\section{Hazard assessors}

\section{Hazard assessors shall:}

Use their best endeavours to command the trust and confidence of the users of hazard assessments; and

Only offer hazard assessments that they are competent, and have the capacity and resources, to provide.
A hazard assessment should be relevant to end-users' demands for scientific input, and sensitive to competing demands relating to the scope, precision and timing of that input.

Communicated clearly: (1) using words, numbers, terms and graphics that are readily understandable to end-users; (2) in a user-friendly format; and (3) accommodating the known strengths and weaknesses of end-user thought processes to ensure that users can easily extract meaning.

To nurture the willingness of end-users to receive and trust scientific advice and make informed decisions based upon the quality of existing relationships, hazard assessors should ensure that: (1) they act always with honesty, integrity, independence and impartiality; and (2) their actions are candid, competent, consistent, open and accountable.

An increasingly wide range of services is sought from volcanologists and bare characterisations of the temporal, spatial and physical parameters of volcanic hazard scenarios (e.g. lahar hazard zone maps) are often accompanied by advice that sometimes includes advice about hazard and risk mitigation issues (e.g. volcano-wide alert levels).

Volcanologists are exposed to new managerial hazards, and vulnerable to managerial risks, when they stray, for whatever reason, from their traditional roles and practices (such as providing lahar hazard zone maps) and to provide risk-related advice (such as risk alert levels based upon lahar hazard zones). The 'exposure' comes from volcanologists extending their scientific advisory role; the 'vulnerability' is derived from any
Chakraborty 2011

Sorensen and Mileti 1987; Punongbayan et al. 1996; Nature 1997; Newhall et al. 1999; Barclay et al. 2008; Chakraborty 2011; Alemanno 2011; Doyle et al. 2014.

Voight 1996; Chakraborty 2011

Hill et al. 2013; Aspinall and Cooke 2013.

Fiske 1984; Newhall and Punongbayan 1996; Driedger et al. 2008; Frenzen and Matarrese 2008; OECD 2015.

Bretton et al. 2015; OECD 2015; Bretton and Aspinall 2017. 
Table 8 Prototype Code of Practice and guidance for volcanic hazard assessments (Continued)

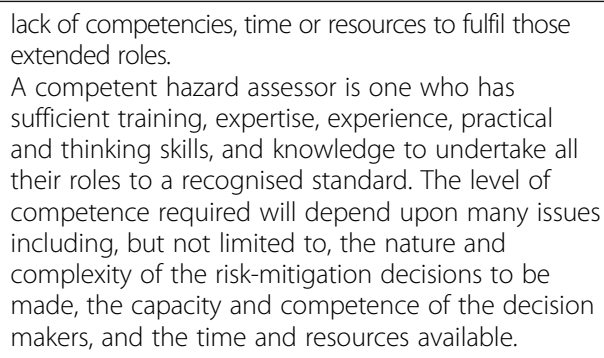

- Enhance the governance of managerial risks (i.e. promote "getting smarter" Bretton et al. 2015, 19), by identifying managerial hazards at the interface, and mitigating avoidable managerial risks:

- by structured delineation of the role of interface volcanologists;

- by structured consideration of all necessary role competencies (including education, training, expertise, experience, skills and knowledge);

- by careful recruitment and selection to meet those competencies

- by structured identification of all competency shortfalls; and

- by structured mitigation of those shortfalls by the provision of suitable and sufficient: (a) information, education, supervision, training, coaching; and (b) time and other resources.

All stakeholders at the interface (and not just volcanologists) should have clear roles, responsibilities, resources and rights to guide their actions and interactions (Simoncini 2014; UN/ISDR 2015; Bretton et al. 2015; Scolobig 2015), and these should be driven by and reflect the stakeholder-negotiated contextualisation practices to which reference has already been made. Stakeholders should also value and accept the principles they have negotiated so that no stakeholder is tempted or pressurised to bend or ignore them, or the legal mandates upon which they are based.

By arguing the merits of contextualised hazard assessments, we must consider all foreseeable consequences. Volcanologists may be exposed to new managerial hazards and will be vulnerable to managerial risks if they are not competent or lack either the time or suitable resources to fulfil more extensive and complex roles. In the absence of both careful planning and clear agreed governance roles at the interface, changed roles may result in: (1) an unstructured blurring of the boundaries between the physical, societal and managerial dimensions of risk governance; (2) the interface challenges and resulting behaviour detailed in Tables 2 and 3; (3) contextualisation that is in disequilibrium and unbalanced, and fails to preserve traditional standards of good science; and (4) foreseeable legal and other consequences (Scolobig 2015; Bretton et al. 2015).

Quality regulation is intended to support the three interface goals, referred to above, whilst actively mitigating the managerial risks posed to volcanologists by role changes. In our first paper we referred to six possible sources of quality regulation, namely: external, collective or self, employer, personal, expert and negotiated. Our proposed quality standards can be used to discuss and develop stakeholder-negotiated regulation norms and, over longer periods, may influence the other five sources of regulation. By enhancing the clarity of relevant and effective quality standards and reducing the unconstrained influences of stakeholders, they are intended to produce contextualisations that are more likely to be in equilibrium and balanced as illustrated in Fig. 1.

\section{Conclusions}

In the absence of relevant quality standards, the contextualisation of hazard assessments is likely to be methodologically diverse and determined by contingent pressures. An unstructured approach may not lead to acceptable standards of societal risk governance, and may expose volcanologists to managerial hazards, leaving them vulnerable to the legal and other consequences of managerial risks.

We do not advocate acceptance of this status quo but present for consideration four reasoned quality standards (standards of materiality, proximity, comprehensibility and integrity as described earlier), and some general principles. They: (1) are framed by the theoretical choices in our first paper; (2) are focussed upon this paper's characterisations of the existing challenges and resulting behaviour based upon published literature; and (3) reflect current practitioner sentiments and practices evident in new empirical data.

We introduce the concept of the equilibrium of contextualisation in order to illustrate the likely effect of unconstrained stakeholder pressures and risk influences upon the traditional role of volcanologists and the hallmarks of long-established scientific methodologies. Quality standards for contextualisation offer the possibility of hazard assessments having greater validity and utility, when measured by 
reference to the sentiments and actions of their users. They will also mitigate the managerial risks faced by volcanologists undertaking more complex roles in the future.

\section{Endnotes}

1"Hazard communication by volcanologists: Part 1 Framing the case for contextualisation and related quality standards in volcanic hazard assessments" [Bretton et al, J Appl. Volcanol. DOI 10.1186/s13617-018-0077-x, 2018]

${ }^{2}$ The first author did not have the time or funding to interview all 33 survey participants.

${ }^{3}$ Donovan and Oppenheimer $(2014,155)$ note that "the boundaries between providing advice and being involved in decision-making were murky because of the high dependence on scientific advice".

${ }^{4}$ Donovan and Oppenheimer (2012) note that "scientific governance (Irwin 2008) and risk governance (Renn 2008) are much discussed in science and technology studies", and acknowledge that "the demarcation of science, risk and politics is increasingly problematic". They suggest that recent works (e.g. Stirling 2007) "have demonstrated that even the separation of risk assessment and risk management may be an oversimplification".

${ }^{5}$ Renn (2008) identifies the risk of societal values, and political and other non-scientific choices, influencing the findings of scientific analysis and the consequential biasing of risk-mitigation outcomes. "Risk decisions are, ultimately, public policy choices...Analysis can gather useful information about which trade-offs citizens as individuals would prefer, but scientists cannot and should not be expected to make decisions that involve societal values. A specialist's role is to bring as much relevant knowledge as possible to participants in a decision whose job is to make the value-laden choice. Good science is a necessary - in a fact, an indispensable - but not sufficient basis of good risk characterisation...Risk characterisation requires a sound scientific base, supported by systematic analysis. Of critical importance is maintaining the integrity of the analytical process, in particular protecting it from political and other pressures that may attempt to influence findings or characterisation so as to bias outcomes" [emphasis added] (Renn 2008, 158).

${ }^{6}$ Donovan and Oppenheimer $(2014,157)$ suggest that "a clear definition of the science-policy interface" is required in the context of volcanic risk.

${ }^{7}$ OECD 2015, 32 note "In many countries, scientific advisory bodies that are called upon in emergency situations are embedded into civil protection structures or formally exist under one or several ministries or governmental agencies. Independent science bodies may also be called upon to provide scientific advice during crisis situations. The boundaries between playing an advisory role and direct involvement in decision-making are not always clear for these various structures and this can undermine any advice that is given. Although well-established advisory systems often have a clear definition of their role and the roles of their experts, the advisory and decision-making responsibilities in crisis situations can easily be confused."

${ }^{8}$ The importance that interviewees attached to scientific independence and freedom for value is supported by Pierson et al. (2014) who suggest values of 'independence' and 'impartiality' enhance perceptions that scientists have integrity and, with the further perceived qualities of 'reliability,' 'competence' and 'openness', are trustworthy.

${ }^{9}$ One known exception is the International Association of Volcanology and Chemistry of the Earth's Interior (IAVCEI) Subcommittee for Crisis Protocols "Professional conduct of scientists during volcanic crises" (Newhall et al. 1999) which, under the heading "Exaggerated statements of risk, or, conversely, overly reassuring statements about safety of an area when significant risk exists" stated "The best protection against unintentional exaggeration of insufficient statements is peer review of all estimates of danger. A crisis situation makes peer review difficult but very important, some oral or written review is usually possible during a team meeting or lull in the unrest (Newhall et al. 1999, 330)".

10" [Analysis] uses rigorous, replicable methods, evaluated under the agreed protocols of an expert community - such as those of disciplines in the natural, social, or decision sciences, as well as mathematics, logic and the law - to arrive at answers to factual questions. It operates on the assumption that facts can be found through an objective, that is, dispassionate and impartial) examination of phenomena" (US/NRC 1996, 73).

11"In fact, according to [the L'Aquila verdict], the significance of the opinion issued by the scientists in that case is directly linked to their membership of an administrative body charged with specific competence and tasks by the legislation. If the scientists had exclusively expressed the opinion as mere experts or scholars, the effects of such an opinion would have been limited to their scientific community; but since they were involved in the regulatory process as members of an administrative Commission, their opinion produces some legal effects on those parties involved in the mitigation process as both regulators and recipients....Risk communication...played a key role in the allocation of the criminal liability on the Major Risk Commission's members: it was at the heart of the establishment of a causal link between the risk assessment and the victims' decision of staying at home and not taking the normal individual safety precaution against earthquakes... "(Simoncini 2014, 148-149, 152).

12،Lack of dialogue among stakeholders undertaking volcanic risk management hinders agreement in front of decision-making processes" (Pardo et al. 2015, 1 citing King et al. 2007) and increases social vulnerability. 
${ }^{13}$ For information sharing [collaboration] also has implications as it moves people from an individualistic perspective ('my information is best') to an acknowledgement of the collective perspective and role ('my information is one piece in the big picture of response') (Doyle et al. 2015, 23).

${ }^{14}$ Gaillard 2008, 325); see also Dibben and Chester (1999); Kelman and Mather (2008); Gaillard (2008); United Kingdom Government Office for Science (2011); Wilson et al. (2012); Stone et al. (2014); Christie et al. (2015).

\section{Additional files}

Additional file 1: Survey questions. (DOCX $33 \mathrm{~kb}$ )

Additional file 2: Survey and interview participants. (DOCX $24 \mathrm{~kb}$ )

Additional file 3: Sources that influenced the survey drafting. (DOCX $28 \mathrm{~kb}$ )

Additional file 4: Ethical agreement. (DOCX $24 \mathrm{~kb}$ )

\section{Abbreviations}

EE: Expert elicitation; IATA: International Air Transport Association; IAVCEl: International Association of Volcanology and Chemistry of the Earth's Interior; IFRC: International Federation of Red Cross and Red Crescent Societies; NZ/MCDEM: New Zealand Ministry of Civil Defence \& Emergency Management; OECD: Organisation for Economic Co-operation and Development; SAC: Scientific Advisory Committee; UK: United Kingdom; UK/GOS: UK Government Office for Science; UN: United Nations; UN/DP: UN Development Programme; UN/ISDR: UN International Strategy for Disaster Reduction; US: United States of America; US/NRC: National Research Council of the US; USGS: US Geological Survey; VALS: Volcano alarm level systems; VUELCO: Volcanic Unrest in Europe; Latin America: Phenomenology, eruption precursors, hazard forecast, and risk mitigation; VUSE: Volcanic Unrest Simulation Exercises; WBGU: German Advisory Council on Global Change

\section{Acknowledgements}

We are very grateful for critical feedback and constructive criticism from Professor Sir Stephen Sparks and Dr. Sue Loughlin, who were RB's PhD examiners and thereby considered an early version of this paper. Candid and very detailed critiques from Chris Newhall and four reviewers greatly enhanced its final version. We also thank Anne Hunt for her eagle-eyed reading of the manuscript and her suggestions and Dr. Al Tanner who assisted with the design of the figure.

\section{Funding}

The research leading to this paper received funding from the European Union's Seventh Framework Programme (FP7/2007-2013) under grant agreement No. 282759 'VUELCO'

\section{Availability of data and materials}

Redacted copies of the surveys and interview transcripts could be prepared on request from the first author subject to the terms of the ethical agreement in Additional file 4.

\section{Authors' contributions}

RJB undertook the research and most of the related analysis and manuscript drafting. JG, RC contributed to the overall structuring and purpose of the paper and its methodology, findings and conclusions. All authors edited, read and approved the final manuscript.

\section{Authors' information}

RB graduated from UOB with a LLB (Hons) Law degree in 1975 and has practised as a UK lawyer since 1978. For most of his career he was a litigation solicitor specialising in regulatory law - in particular, occupational health and safety law compliance - and, in later years, the defence of criminal prosecutions against utility companies following serious accidents and fatalities. In 2009 RB returned to UOB graduating with a BSC (Hons) in Geology in 2012 and a PhD in 2017. His PhD thesis was entitled "Hazard Communication by Volcanologists: The case for contextualisation and related quality standards". RB has the unusual, if not unique, distinction of over 39 years' experience of legal practice in the relevant field of regulatory law (health \& safety) supplemented by more recent academic qualifications in geology. $J G$ is Professor of Volcanology at UOB with broad interests in volcanological research.

RC is a social scientist and a Senior Lecturer in East Asian Studies at UOB.

\section{Ethics approval and consent to participate}

The research used the ethical agreement in Additional file 4, and informed consent was obtained from all survey participants and interviewees. With their express consent, the names of all survey participants and interviewees are listed in Additional file 2 and a minimum degree of anonymity was guaranteed by ensuring that specific responses could not be linked to identifiable individuals.

\section{Competing interests}

The authors declare that they have no competing interests.

\section{Publisher's Note}

Springer Nature remains neutral with regard to jurisdictional claims in published maps and institutional affiliations.

\section{Author details}

${ }^{1}$ School of Earth Sciences, University of Bristol, Wills Memorial Building, Queens Road, Bristol BS8 1RJ, UK. ${ }^{2}$ School of Sociology, Politics \& International Studies, University of Bristol, 4 Priory Road, Bristol BS8 1TU, UK.

Received: 6 November 2017 Accepted: 21 August 2018

Published online: 02 October 2018

\section{References}

Alemanno A. What happened and lessons learned: a European and international perspective governing disasters. In: Alemanno A, editor. The challenges of emergency risk regulation. Cheltenham and Northampton: Edward Elgar; 2011. p. 3-12.

Alexander DE. The L'Aquila Earthquake of 6 April 2009 and Italian Government Policy on Disaster Response. J Nat Res Pol Res. 2010;2(4):325-42. https://doi. org/10.1080/19390459.2010.511450.

Alexander DE. An evaluation of medium-term recovery processes after the 6 April 2009 earthquake in L'Aquila, Central Italy. Environ Hazards. 2013;12(1):60-73. https://doi.org/10.1080/17477891.2012.689250.

Alexander DE. Communicating earthquake risk to the public: the trial of the "L'Aquila Seven". Nat Hazards. 2014a; https://doi.org/10.1007/s11069-0141062-2.

Alexander DE. Reply to a comment by Franco Gabrielli and Daniela Di Bucci: "Communicating earthquake risk to the public: the trial of the 'L'Aquila Seven". Nat Hazards. 2014b; https://doi.org/10.1007/s11069-014-1323-0.

Aspinall WP. Check your legal position before advising others. Nature. 2011;477: 250. https://doi.org/10.1038/477251a.

Aspinall WP. Comment on "Social studies of volcanology: knowledge generation and expert advice on active volcanoes" by Amy Donovan, Clive Oppenheimer and Michael Bravo [Bull Volcanol (2012) 74:677-689]. Bull Volcanol. 2012;74:1569-70.

Aspinall WP, Cooke RM. Expert judgement and the Montserrat Volcano eruption. In: Mosleh A, Bari RA, editors. Proceedings of the 4th International Conference of Probabilistic Safety Assessment and Management PSA4 September 13-18 1998, New York City, USA, vol. 3; 1998. p. 2113-8.

Aspinall WP, Cooke RM. Quantifying scientific uncertainty. In: Rougier J, Sparks RSJ, Risk HL, editors. Risk and uncertainty assessment for natural hazards. Cambridge: Cambridge University Press; 2013.

Barberi F, Carapezza ML. The problem with volcanic unrest: the Campi Flegrei case history. In: Scarpa R, Tilling Rl, editors. Monitoring and mitigation of volcano hazards. Berlin: Springer; 1996. p. 771-84.

Barclay J, Haynes K, Mitchell T, Solana C, Teeuw R, Darnell A, Crosweller HS, Cole P, Pyle D, Lowe C, Fearnley C, Kelman I. Framing volcanic risk communication within disaster risk reduction: finding ways for the social and physical sciences to work together. In: Liverman DGE, Pereira CPG, Marker B, editors. Communicating environmental geoscience geological society, vol. 305. London: Special Publications; 2008. p. 163-77. https://doi.org/10.1144/ SP305.14. 
Bartolini S, Cappello A, Martin J, Del Negro C. QVAST: a new Quantum GIS plug for estimating volcanic susceptibility. Nat Hazards Earth Syst Sci. 2013;13: 3013-3-34.

Beven KJ, Aspinall WP, Bates PD, Borgomeo E, Goda K, Hall JW, Page T, Phillips JC, Rougier JT, Simpson M, Stephenson DB, Smith PJ, Wagener T, Watson M. Epistemic uncertainties and natural hazard risk assessment - part 1: a review of the issues. Nat Hazards Earth Syst Sci Discuss. 2015;3:7333-77, www.nathazards-earth-syst-sci-discuss.net/3/7333/2015/. https://doi.org/10.5194/ nhessd-3-7333-2015.

Bohnenblust $\mathrm{H}$, Slovic $\mathrm{P}$. Integrating technical analysis and public values in riskbased decision making. Reliab Eng Syst Saf. 1998;59:151-9.

Bretton RJ, Aspinall WP. Risk assessments face scrutiny. Nature. 2017;550:188.

Bretton RJ, Gottsmann J, Aspinall WP, Christie R. Implications of legal scrutiny processes (including the L'Aquila trial and other recent court cases) for future volcanic risk governance. J Appl Volcanol. 2015;4:18. https://doi.org/10.1186/ s13617-015-0034-x

Bretton RJ, Gottsmann J, Aspinall WP, Christie R (2018) Hazard communication by volcanologists: part 1 - framing the case for contextualisation and related quality standards in volcanic hazard assessments [TO BE COMPLETED].

Bruijn JA, ten Heuvelhof EF. Scientific expertise in complex decision-making processes. Sci Public Policy. 1999;26(3):151-61.

Bryman A. Social research methods. 4th ed. New York: Oxford University Press Inc.; 2012.

Chakraborty S. The challenge of emergency risk communication: lessons learned in trust and risk communication from the volcanic ash crisis. In: Alemanno A, editor. The challenges of emergency risk regulation. Cheltenham and Northampton: Edward Elgar; 2011. p. 80-97.

Charmaz K. The grounded theory model: an explication and interpretation. In: Emerson RM, editor. Contemporary field research: a collection of readings. Boston: Little, Brown; 1983.

Charmaz K. Constructing ground theory: a practical guide through qualitative analysis. London: Sage; 2006.

Christie R, Cooke O, Gottsmann J. Fearing the knock on the door: critical security studies insights into limited cooperation with disaster management regimes. J Appl Volcanol. 2015;4:19. https://doi.org/10.1186/s13617-015-0037-7.

Cooke RM. Messaging climate change uncertainty. Nat Clim Chang. 2015;5(1):810. https://doi.org/10.1038/nclimate2466. http://www.nature.com/nclimate/ journal/v1035/n1031/abs/nclimate2466.html\#supplementary-information

Cornell SE, Jackson MS. Social science perspectives on natural hazards risk and uncertainty. In: Rougier J, RSJ S, Hill L, editors. Risk and uncertainty assessment for natural hazards. Cambridge: Cambridge University press; 2013. p. 502-47.

Department of Farming and Rural Affairs DEFRA - The Central Science Laboratory (2007) Comparative review of risk terminology - Final Report November 2007 Department of Farming and Rural Affairs, Sand Hutton, York YO12 1LW

Dibben C, Chester DK. Human vulnerability in volcanic environments: the case of Furnas, Sao Miguel, Azores. J Volcanol Geotherm Res. 1999;92:133-50.

Donovan A, Oppenheimer C. Governing the lithosphere: Insights from Eyjafjallajökull concerning the role of scientists in supporting decisionmaking on active volcanoes. J Geophys Res. 2012;117:B03214. https://doi.org/ 10.1029/2011JB009080,2012.

Donovan A, Oppenheimer C. Science, policy and place in volcanic disasters: insights from Montserrat. Environ Sci Pol. 2014;38:150-61.

Doyle EEH, McClure J, Johnston DM, Paton D. Communicating likelihoods and probabilities in forecasts of volcanic eruptions. J Volcanol Geotherm Res. 2014:272:1-15

Doyle EEH, Paton D, Johnston DM. Enhancing scientific response in a crisis: evidence-based approaches from emergency management in New Zealand. J Appl Volcanol. 2015;4:1. https://doi.org/10.1186/s.13617-014-0020-8.

Driedger C, Neal CA, Knappenberger TH, Needham DH, Harper RB, Steele WP. Hazard information management during the autumn 2004 reawakening of Mount St. Helens Volcano, Washington. In: Sherrod DR, Scott WE, Stauffer PH, editors. A volcano rekindled: the renewed eruption of Mount St. Helens, 2004-2006, Edited by, US Geological Survey Professional Paper 1750, 2008; 2008.

Fearnley CJ. Assigning a volcano alert level: negotiating uncertainty, risk, and complexity in decision-making processes. Environ Plan A. 2013;45(8):1891-911. https:/doi.org/10.1068/a4542.

Fischhoff B. The sciences of science communication. Proc Natl Acad Sci. 2013; $111($ suppl. 4):14033-9.
Fiske R. Volcanologists, journalists, and the concerned local public: a tale of two crises in the Eastern Caribbean. In: Explosive volcanism: inception, evolution and hazards. Washington: Geophys. Study Committee, National Research Council, National Academy Press; 1984. p. 170-6.

Francis P, Oppenheimer C. Volcanoes. Oxford: Oxford University Press; 2004

Freer J, Beven KJ, Neal J, Schumann G, Hall J, Bates P. Flood risk and uncertainty. In: Rougier J, Sparks RSJ, Risk HL, editors. Risk and uncertainty assessment for natural hazards. Cambridge: Cambridge University Press; 2013.

Frenzen PM, Matarrese MT. Managing public and media response to a reawakening volcano: Lessons from the 2004 Eruptive Activity of Mount St. Helens. In: Sherrod DR, Scott WE, Stauffer PHA, editors. Volcano rekindled: the renewed eruption of Mount St. Helens, 2004-2006, US. Geological Survey Professional Paper 1750, 2008; 2008

Freudenburg WR. Perceived risk, real risk: social science and the art of probabilistic risk assessment. Science. 1988;242:44-9.

Funtowicz SO, Ravetz JR. Uncertainty and quality in science for policy. Dordrecht: Kluwer; 1990.

Funtowicz SO, Ravetz JR. Three types of risk assessment and the emergence of post-normal science. In: Krimsky S, Golding D, editors. Social theories of risk. Westport and London: Praeger; 1992. p. 251-73.

Gabrielli F, Di Bucci D. Comment on "Communicating earthquake risk to the public: the trial of the 'L'Aquila Seven" by David Alexander. Nat Hazards. 2014; https://doi.org/10.1007/s11069-014-1322-1.

Gaillard J-C. Alternative paradigms of volcanic risk perception: the case of Mt. Pinatubo in the Philippines. J Volcanol Geotherm Res. 2008;172(3-4):315-28.

Glaser BG, Strauss AL. The discovery of grounded theory: strategy for qualitative research. Chicago: Aldine; 1967.

Grabill JT, Simmons WM. Toward a critical rhetoric of risk communication: Producing citizens and the role of technical communicators. Tech Commun Q. 1998;7(4):415-41. https://doi.org/10.1080/10572259809364640.

Hadfield P. Mount Mayon blows without warning. New Sci. 1993;1993:1860. Hicks A, Barclay J, Simmons P, Loughlin S. An interdisciplinary approach to volcanic risk reduction under conditions of uncertainty: a case study of Tristan da Cunha. Nat Hazards Earth Syst Sci Discuss. 2013;1(7779-7820): 20913 www.nat-hazards-earth-syst-sci-discuss.net/1/7779/2013/. https://doi. org/10.5194/nhessd-1-7779-2013.

Hill $L$, Sparks RSJ, Rougier JC. Risk assessment and uncertainty in natural hazards. In: Rougier J, Sparks RSJ, Risk HL, editors. Risk and uncertainty assessment for natural hazards. Cambridge: Cambridge University Press; 2013.

Hincks TK, Jean-Christophe Komorowski J-C, Sparks SR, Aspinall WP. Retrospective analysis of uncertain eruption precursors at La Soufrière volcano, Guadeloupe, 1975-77: volcanic hazard assessment using a Bayesian belief network approach. J Appl Volcanol. 2014;3:3. https://doi.org/10.1186/2191-5040-3-3.

Horlick-Jones T. Meaning and contextualisation in risk assessment. Reliab Eng Syst Saf. 1998:59:79-89.

International Air Transport Association (IATA) Economic briefing 2010, www.iata. org/economics

International Risk Governance Council (IRGC). Risk governance - towards an integrated approach, White Paper No.1 O. Renn with an Annex by P. Graham. Geneva: IRGC; 2005.

Irwin A. STS perspectives on scientific governance. In: Hackett EJ, et al., editors. The Handbook of Science and Technology Studies, 3rd ed. Cambridge: MIT Press; 2008. p. 583-608.

Jasanoff S. Science and the statistical victim: modernising knowledge in the breast implant litigation. Soc Stud Sci Law. 2002;32:37-69.

Johnson C, Jeunemaitre A. Risk and the role of scientific input for contingency planning: a response to the April 2010 Eyjafjallajökull volcano eruption. In: Alemanno A, editor. The challenges of emergency risk regulation. Cheltenham and Northampton: Edward Elgar; 2011. p. 51-64.

Jolly AD, Cronin SJ. From eruption to end-user: bridging the sciencemanagement interface during the 2012 Te Maari eruption, Tongariro volcano, New Zealand. J Volcanol Geotherm Res. 2014;286:183.

Kahneman D, Tversky A. Prospect theory: an analysis of decision under risk. Econometrica. 1979:47(2):263-91.

Kelman I, Mather TA. Living with volcanoes: the sustainable livelihoods approach for volcano-related opportunities. J Volcanol Geotherm Res. 2008;172:189-98

King DNT, Goff J, Skipper A. Māori Environmental Knowledge and natural hazards in Aotearoa-New Zealand. J R Soc N Z. 2007;37(2):59-73.

Komorowski J-C, Hincks T, Sparks RSJ, Aspinall W, CASAVA ANR project consortium. Improving crises decision-making at times of uncertain volcanic 
unrest (Guadeloupe 1976). In: Loughlin SC, Sparks RSJ, Brown SK, Jenkins SF Vye-Brown C, editors. Global volcanic hazards and risk. Cambridge University Press: Cambridge; 2015.

Laudan L. The pseudo-science of science? The demise of the demarcation problem. In: Laudan L, editor. Beyond positivism and relativism: theory, method and evidence. Boulder: Westview Press; 1996. p. 166-92.

Leonard GS, Stewart C, Wilson TM, Procter JN, Scott BJ, Keys HJ, Jolly GE, Wardman JB, Cronin SJ, MCBride SK. Integrating multidisciplinary science, modelling and impact data into evolving, syn-event volcanic hazard mapping and communication: a case study from the 2012 Tongariro eruption crisis, New Zealand. J Volcanol Geotherm Res. 2014;286:208-32.

Lipshitz R, Klein G, Orasanu J, Salas E. Focus article: taking stock of naturalistic decision making. J Behav Decis Mak. 2001;14(5):331-52.

Lupton D. Risk. London and New York: Routledge; 1999.

Macrae D. Which risk and who decides when there are so many players. In: Alemanno A, editor. The challenges of emergency risk regulation. Cheltenham and Northampton: Edward Elgar; 2011. p. 3-12.

Marrero JM, García A, Llinares Á, Berrocoso M, Ortiz R. Legal framework and scientific responsibilities during volcanic crises: the case of the El Hierro eruption (2011-2014). J Appl Volcanol. 2015;4:13. https://doi.org/10.1186/ s13617-015-0028-8.

Marti J. Scientific communication of uncertainty during volcanic emergencies. In: Loughlin SC, Sparks RSJ, Brown SK, Jenkins SF, Vye-Brown C, editors. Global volcanic hazards and risk. Cambridge: Cambridge University Press; 2015.

Marzocchi W, Bebbington MS. Probabilistic eruption forecasting at short and long time scales. Bull Volcanol. 2012;74:1777-805. https://doi.org/10.1007/s00445012-0633-x

Marzocchi W, Newhall C, Woo G. The scientific management of volcanic crises. J Volcanol Geotherm Res. 2012; https://doi.org/10.1016/j.volgeorgres.2012.08.016.

Mayberry G. The US volcano disaster assistance program: helping to save lives by reducing the risk from volcanic eruptions. 2016. http://siteresources. worldbank.org/INTLACREGTOPURBDEV/Resources/mayberry_WorldBank.pdf. Accessed on 6 June 2016

McGuire WJ, Kilburn CRJ. Forecasting volcanic events: some contemporary issues. Geol Rundsch. 1997;86:439-45.

McGuire WJ, Solana MC, Kilburn CRJ, Sanderson D. Improving communication during volcanic crises on small, vulnerable islands. J Volcanol Geotherm Res. 2009;183:63-75.

Mellor F. Negotiating uncertainty: asteroids, risk and the media. Public Underst Sci. 2008; https://doi.org/10.1177/0963662507087307.

Merz B, Thieken AH. Separating natural and epistemic uncertainty in flood frequency analysis. J Hydrol. 2005;309(1-4):114-32.

Metzger P, D'Ercole R, Sierra A. Political and scientific uncertainties in volcanic risk management: the yellow alert in Quito in October 1998. GeoJournal. 1999:49:213-21.

Mothes PA, Yepes HA, Hall ML, Ramón PA, Steel AL, Ruiz MC. The scientificcommunity interface over the fifteen-year eruptive episode of Tungurahua Volcano, Ecuador. J Appl Volcanol. 2015;4:9. https://doi.org/10.1186/s13617015-0025-y

Nature (1997) Editorial - cooperation can help to get the message across. Vol. 388 Issue No. 66373 July 19971

Neuberg J. Thoughts on ethics in volcanic hazard research, Chapter 24 in Geoethics, M. Wyss \& S. Peppoloni (Eds.), Elsevier; 2015. p. 305-12. https://doi. org/10.1016/B978-0-12-799935-7.00024-1

Newhall C, Aramaki S, Barberi F, Blong R, Calavache M, Cheminee J-L, Punongbayan R, Siebe C, Simkin T, Sparks RSJ, Tjetjep W. International Association of Volcanology and Chemistry (IAVCEI) Subcommittee for Crisis Protocols - Professional conduct of scientists during volcanic crises. Bull Volcanol. 1999;60:323-34

Newhall C, Aramaki S, Barberi F, Blong R, Calavache M, Cheminee J-L, Punongbayan R, Siebe C, Simkin T, Sparks RSJ, Tjetjep W, Djumarna A. International Association of Volcanology and Chemistry (IAVCEI) subcommittee for crisis protocols reply. Bull Volcanol. 2000;62:62-4.

Newhall CG, Punongbayan RS. The narrow margin of successful volcanic-risk mitigation. In: Scarpa R, Tilling Rl, editors. Monitoring and mitigation of volcano hazards. Berlin: Springer; 1996. p. 807-38.

Nowotny $\mathrm{H}$. Re-thinking science: from reliable knowledge to socially robust knowledge. In: Lepenies W, editor. Entangled histories and negotiated universals - centers and peripheries in a changing world campus Verlag, Frankfurt \& New York; 2003
NZ/MCDEM. Exercise Ruaumoko 2008: final exercise report. Wellington: Ministry of Civil Defence \& Civil Management; 2008.

OECD. Scientific advice for policy making: the role and responsibility of expert bodies and individual scientists, OECD science, technology and industry policy papers, no. 21. Paris: OECD Publishing; 2015. https://doi.org/10.1787/ 5js3311jcpwb-en

Papale P. Rational volcanic hazard forecasts and the use of volcanic alert levels. J Appl Volcanol. 2017;6:13. https://doi.org/10.1186/s13617-017-0064-7.

Pardo N, Wilson H, Procter JN, Lattughi E. Black T (2015) Bridging Māori indigenous knowledge and western geosciences to reduce social vulnerability in active volcanic regions. J Appl Volcanol. 2015;4:5. https://doi. org/10.1186/s13617-014-0019-1.

Paton D, Johnston DM, Houghton BF. Organisational response to a volcanic eruption. Disaster Prev Manag. 1998;7:5-13. https://doi.org/10.1108/ 09653569810206226

Paton D, Johnston DM, Houghton BF, Flin R, Ronan K, Scott B. Managing natural hazard consequences: planning for information management and decision making. J Am Soc Prof Emerg Plan. 1999;6:37-47.

Peterson DW. Mitigation measures and preparedness plans for volcanic emergencies. In: Scarpa R, Tilling Rl, editors. Monitoring and mitigation of volcano hazards. Berlin: Springer; 1996. p. 701-18.

Pierson TC, Wood NJ, Dreidger CL. Reducing risk from lahar hazards: concepts, case studies, and roles for scientists. J Appl Volcanol. 2014;3:16.

Potter SH, Jolly GE, Neall VE, Johnston DM, Scott BJ. Communicating the status of volcanic activity: revising New Zealand's volcanic alert level system. J Appl Volcanol. 2014;3:13.

Punongbayan RS, Newhall CG, Bautista MLP, et al. Eruption hazard assessments and warnings. In: Newhall CG, Punongbayan RS, editors. Fire and mud: eruptions and lahars of Mount Pinatubo, Philippines. Seattle: University of Washington Press; 1996. p. 67-85.

Renn O. Risk governance - coping with uncertainty in a complex world. London \& New York: Earthscan; 2008.

Ronan KR, Paton DM, Johnston DM, Houghton F. Managing societal uncertainty in volcanic hazards: a multidisciplinary approach. Disaster Prev Manag. 2000; 9(5):339-49.

Rothstein H, Huber M, Gaskell G. A theory of risk colonisation: the spiralling regulatory logics of societal and institutional risk. Econ Soc. 2006;35(1): 91-112.

Rougier J. Quantifying hazard losses. In: Rougier J, Sparks RSJ, Risk HL, editors. Risk and uncertainty assessment for natural hazards. Cambridge: Cambridge University Press; 2013.

Rougier J, Beven KJ. Model data limitations: the sources and implications of epistemic uncertainty. In: Rougier J, Sparks RSJ, Risk HL, editors. Risk and uncertainty assessment for natural hazards. Cambridge: Cambridge University Press; 2013.

Sandri L, Guidoboni E, Marzocchi W, Selva J. Bayesian event tree for eruption forecasting (BET_EF) at Vesuvius, Italy: a retrospective forward application to the 1631 eruption. Bull Volcanol. 2009;71:729-45.

Scolobig A. Brief communication: the dark side of risk and crisis communication: legal conflicts and responsibility allocation. Nat Hazards Earth Syst Sci. 2015; 15:1449-56. https://doi.org/10.5194/nhess-15-1449-2015.

Scolobig A, Mechler R, Komendantova N, Schröter D, Patt A. The co-production of scientific advice and decision making under uncertainty: lessons from the 2009 L'Aquila Earthquake, Italy GRF Davos Planet@Risk, Volume 2, Number 2, April 2014; 2014. p. 71-6.

Simoncini $M$. When science meets responsibility - the major risk commission and the L'Aquila earthquake. EJRR 2/2014 Vol. 3 No. 2; 2014. p. 146-58.

Sobradelo R, Bartolini S, Marti J. HASSET: a probability tool to evaluate future volcanic scenarios using Bayesian inference. Bull Volcanol. 2014;76:770.

Solana MC, Kilburn CRJ, Rolandi G (2008) Communicating eruption and hazard forecasts on Vesuvius, Southern Italy, J Volcanol Geotherm Res 189 (2010) 308-314.

Sorensen JH, Mileti DS. Public warning needs US Geol Surv Open-File Rep 87-269; 1987. p. 9-75.

Spieghalter DJ, Reisch H. Don't know, can't know: embracing deeper uncertainties when analysing risks. Phil Trans R Soc A. 2011;369:4730-50. https://doi.org/10.1098/rsta.2011.0163.

Stein S, Friedrich A. How much can we clear the crystal ball? Astron Geophys. 2014;55(2) https://doi.org/10.1093/astrogeo/atu089.

Stein S, Geller RJ (2012) Communicating Uncertainties in Natural Hazard Forecasts EOS Vol 93 No. 3818 September 2012. 
Stern PC, Fineberg HV (1996) Understanding Risk: Informing Decision in a Democratic Society Editors; Committee on Risk Characterization, National Research Council http://www.nap.edu/catalog/5138.ht/m

Stirling A. Risk, precaution and science: Towards a more constructive policy debate. EMBO Rep. 2007;8:309-15. https://doi.org/10.1038/sj.embor.7400953.

Stirling A. Keep it complex. Nature. 2010;468:1029-31.

Stone J, Barclay J, Simmons P, Cole P, Loughlin S, Ramón MP. Risk reduction through community-based monitoring: the vigías of Tungurahua, Ecuador. J Appl Volcanol Soc Volcanoes. 2014;3:11. https://doi.org/10.1186/s13617-0140011-9.

Strauss A, Corbin JM. Basics of qualitative research: grounded theory and techniques. Newbury Park: Sage; 1990.

Strauss A, Corbin JM. Basics of qualitative research: techniques and procedures for developing grounded theory. Thousand Oaks: Sage; 1998.

UN/ISDR (2015) Sendai framework for disaster risk reduction 2015-30

United Kingdom Government Office for Science (UK/GOS) (2011) Code of practice for advisory committees http:/www.nationalarchives.gov.uk/doc/ open-government-licence

United States National Research Council (US/NRC). Understanding risk: informing decisions in a democratic society, national academy of sciences. Washington, DC: National Academy Press; 1996.

Van Nuffelen DV. The social construction of risk. Belgium: Scientific Bulletin, Federal Agency for Nuclear Control; 2004

Voight B. The management of volcano emergencies: Nevado del Ruiz. In: Scarpa R, Tilling Rl, editors. Monitoring and mitigation of volcano hazards. Berlin: Springer; 1996. p. 719-69.

Voight B. Volcanologists' efforts on Montserrat praiseworthy. Bull Volcanol. 1998; 60:318-3919.

WBGU (German Advisory Council on Global Change). World in transition: strategies for managing global environmental risk, annual report. Heidelberg and New York: Springer; 2000.

Weinberg AM (1972) Science and trans-science science 21 July 1972: 1774045. 211 doi: https://doi.org/10.1126/science.177.4045.211.

Weinberg AM (1992) Nuclear reactions: science and trans-science the American Institute of Physics, New York, USA.

Wilson T, Cole J, Johnston D, Cronin S, Stewart C, Dantas A. Short-and long-term evacuation of people and livestock during a volcanic crisis: lessons from the 1991 eruption of Volcán Hudson, Chile. J Appl Volcanol. 2012;1:2. https://doi. org/10.1186/2191-5040-1-2.

Winson AEG, Costa F, Newhall CG, Woo. An analysis of the issuance of volcanic alert levels during volcanic crisis. J Appl Volcanol. 2014;3:14.

Wynne B. Uncertainty and environmental learning: reconceiving science and policy in the preventive paradigm. Glob Environ Chang. 1992;2:111-27.

\section{Submit your manuscript to a SpringerOpen ${ }^{\circ}$ journal and benefit from:}

- Convenient online submission

- Rigorous peer review

- Open access: articles freely available online

- High visibility within the field

- Retaining the copyright to your article

Submit your next manuscript at $\boldsymbol{\nabla}$ springeropen.com 